Köster [94] conducted SCC tests in aggressive chloride brines (some containing $\mathrm{Mg}$ and $\mathrm{Ca}$ ) at 90,170 , and $200^{\circ} \mathrm{C}$ in the presence and absence of a gamma radiation field $\left(10^{5} \mathrm{rad} / \mathrm{hr}\right)$. They concluded that Ti Grade 7 was resistant to both localized corrosion and SCC in those environments.

In test media relevant to the repository environments, SCC tests were conducted using U-bend (constant deflection) specimens of Ti Grades 7 and 12 [95]. The specimens were exposed for up to 4 years in SCW, SAW, and SDW solutions (Table 3). No SCC failure was observed in these tests [95]. However, in constant load tests where the specimens are loaded significantly above the yield strength, the SCC crack growth initiated in under 1-year of exposure [95].

Andresen, et al. [96] used compact tensile specimens in the as-received and $20 \%$ cold worked state. The specimens were loaded to $30 \mathrm{MPa} \sqrt{\mathrm{m}}$ in the BSW-12 solution (Table 3) at $110^{\circ} \mathrm{C}$ and subjected to very low cyclic loading $(\sim 0.001 \mathrm{~Hz})$. Crack length versus time was monitored in-situ using a reversing DC potential drop technique. A typical result is shown in Figure 15. The loading characteristics were modified at several times through the addition of long hold times at the maximum stress intensity factor $\left(\mathrm{K}_{\max }\right)$ culminating with a very long hold time ( 2000 hours) about 4100 hours into the test. The crack growth rate during this time was about $1.3 \times 10^{-8} \mathrm{~mm} / \mathrm{s}(\sim 0.4 \mathrm{~mm} / \mathrm{yr})$. 


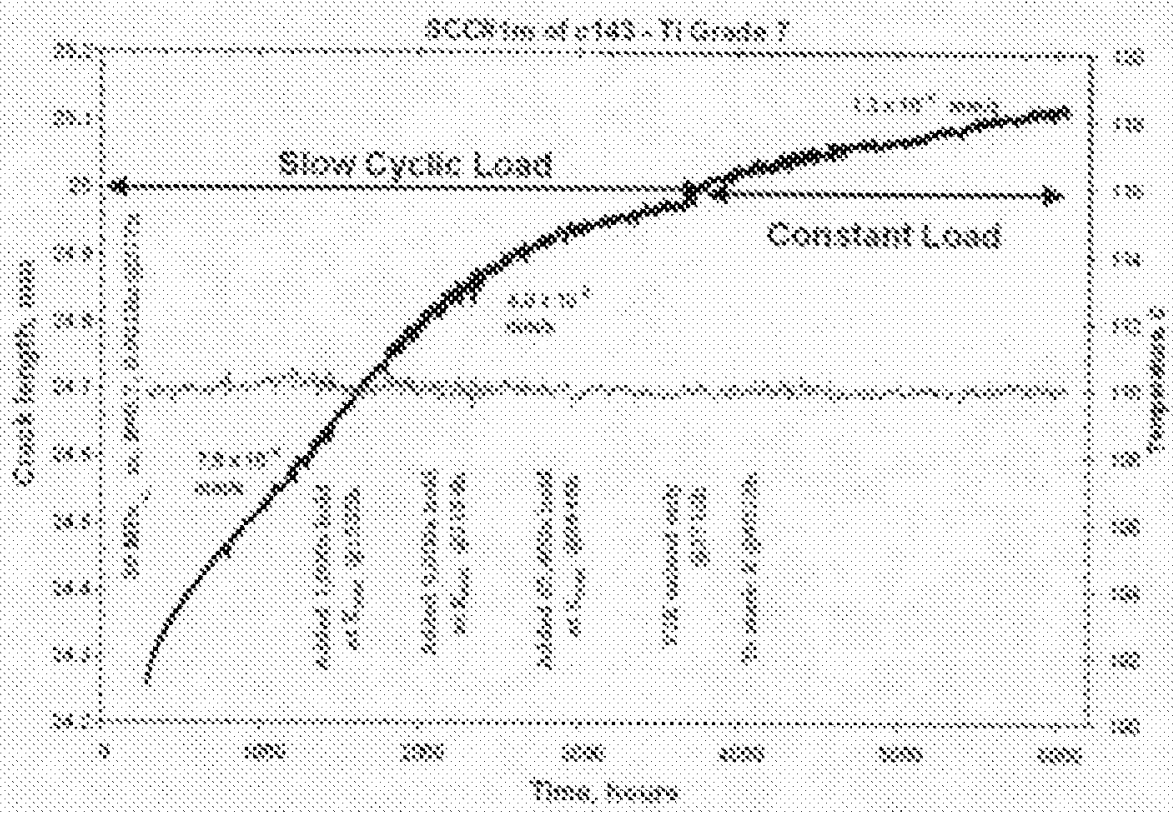

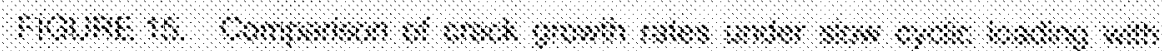

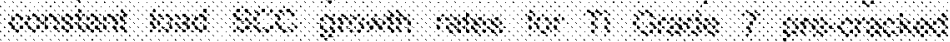

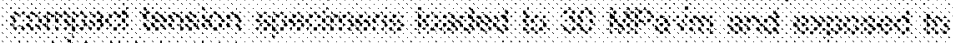

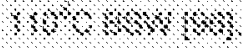

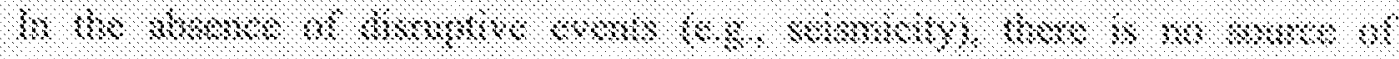

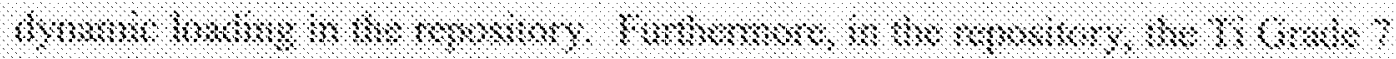

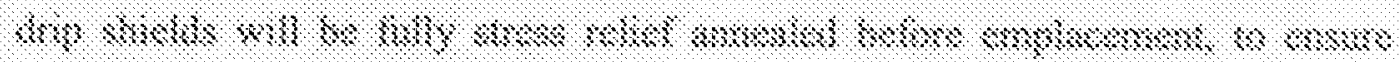

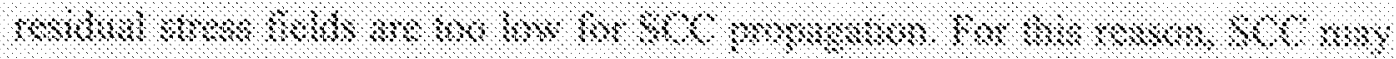

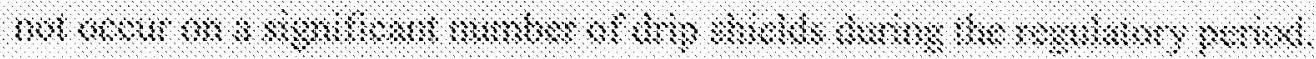

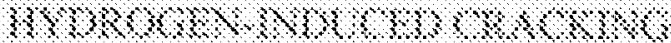

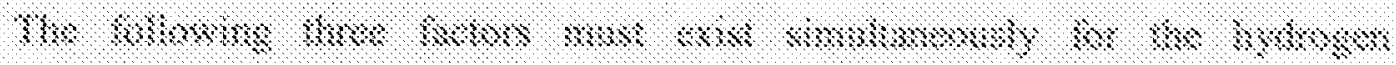

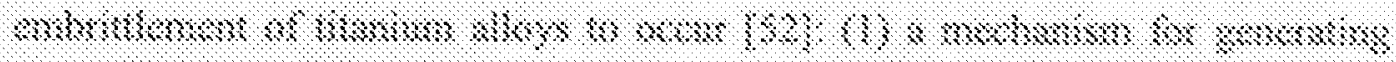

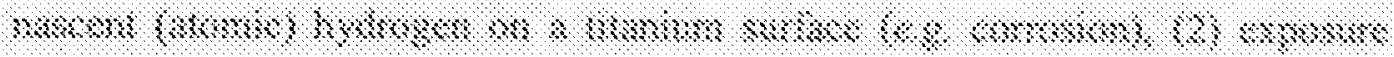

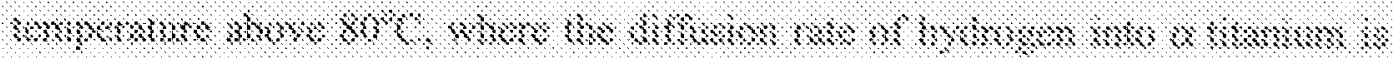




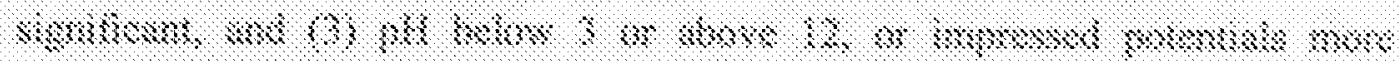

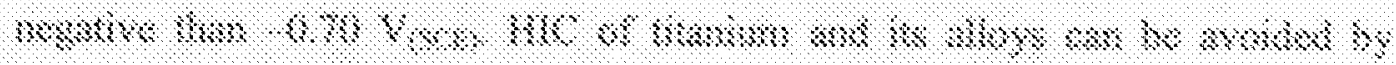

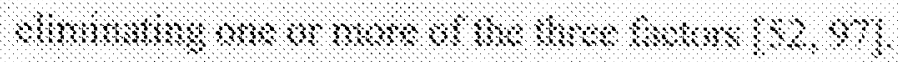

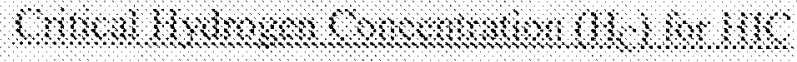

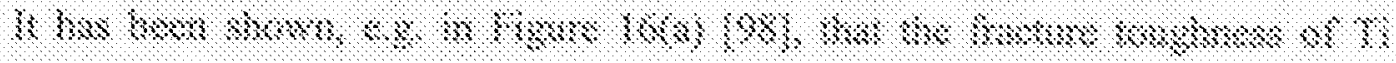

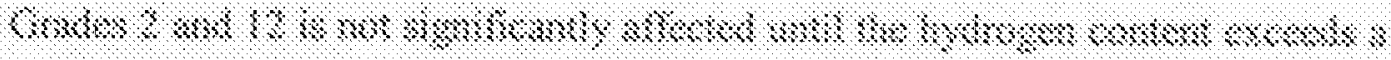

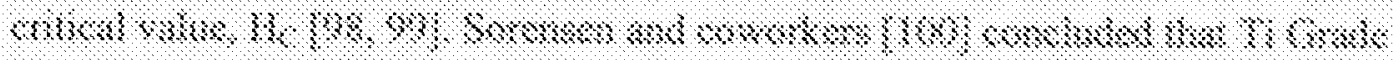

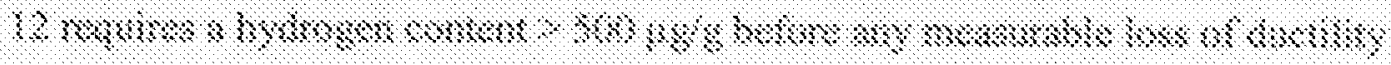

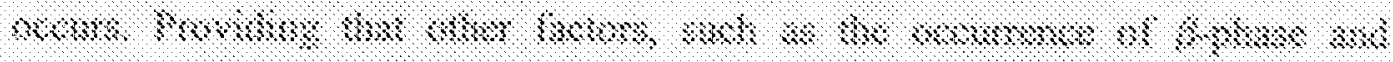

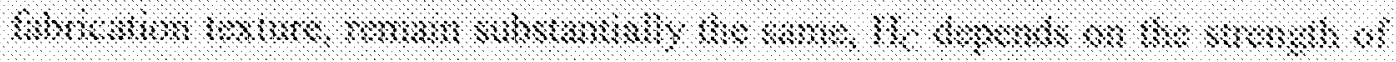

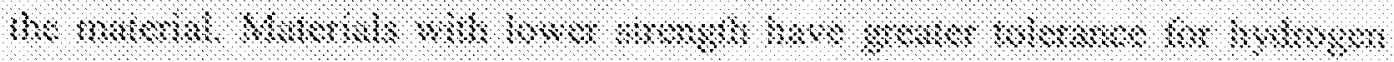

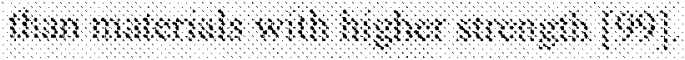
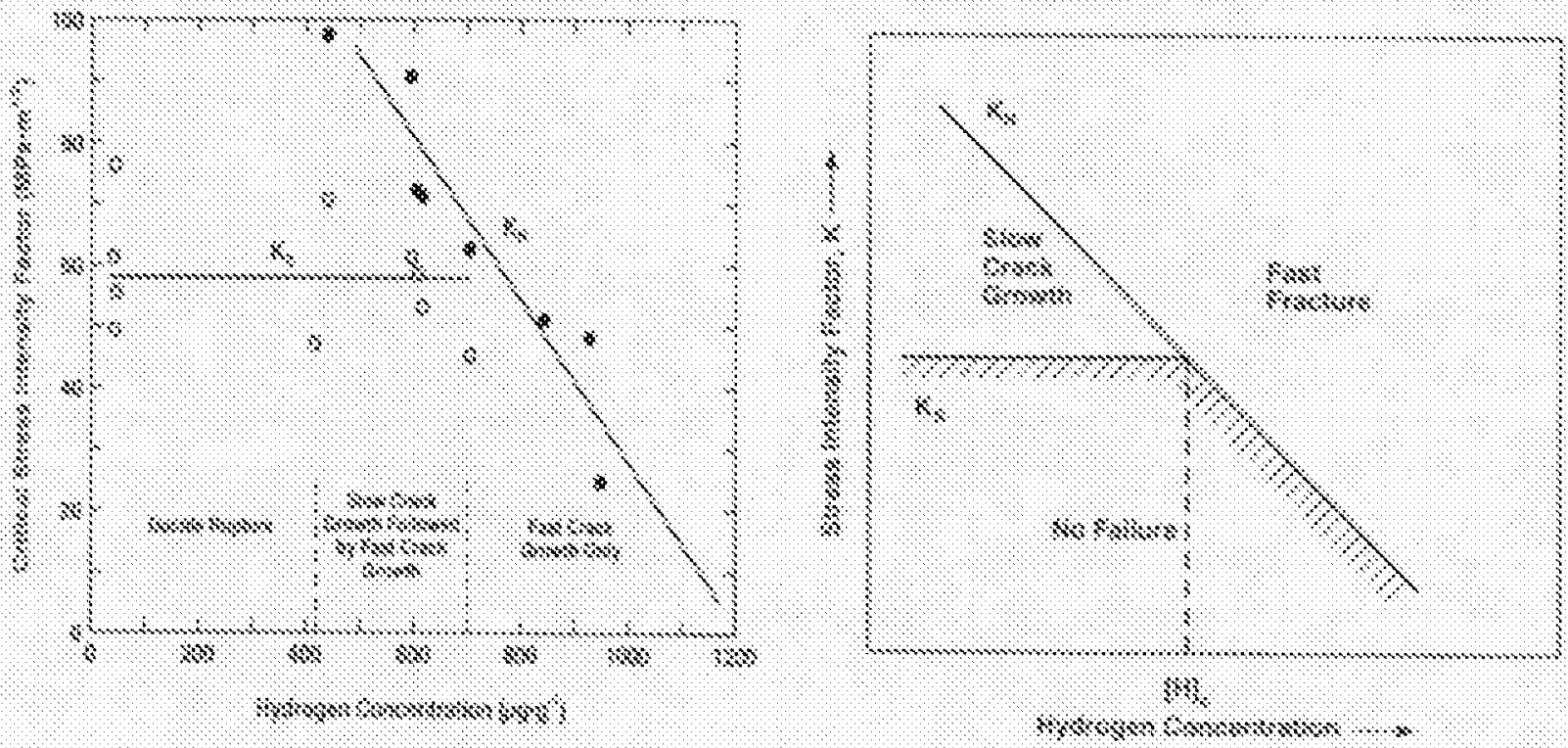
(a)

(b)

FIGURE 16. (a) Variation of the Critical Stress Intensity Factor with Hydrogen Content for Ti Grade 2: o - Slow Crack Growth $\left(K_{s}\right)$; - - Fast Fracture $\left(K_{H}\right)$ [98]; (b) Schematic showing combinations of stress intensity factor and hydrogen concentration leading to fast fracture $\left(\mathrm{K}_{\mathrm{H}}\right)$ or slow crack growth $(\mathrm{Ks})$, or to no failure [101].

Figure 16b [101], illustrates how such experiments can be used to identify the critical hydrogen content $\left(\mathrm{H}_{\mathrm{C}}\right)$. Based on such measurements, values of $\mathrm{H}_{\mathrm{C}}$ of 500 to $800 \mu \mathrm{g} / \mathrm{g}$ (Ti Grade 2) and 400 to $600 \mu \mathrm{g} / \mathrm{g}$ (Ti Grade 12) have been determined $[98,102]$.

Ikeda and Quinn reported that the $\mathrm{H}_{\mathrm{C}}$ value for Ti Grade 16 is between 1000 and $2000 \mu \mathrm{g} / \mathrm{g}[39,40] .$. Since both Ti Grade 7 and Ti Grade 16 are virtually identical except for palladium content (Table 1) and are $\alpha$-alloys containing minimal amounts of $\beta$-phase, it is reasonable to expect that both alloys will exhibit very similar responses to applied stresses in acidic environments. Thus, the controlling factor in determining the $\mathrm{H}_{\mathrm{C}}$ will be the solubility of the hydrogen in the alloy which increases with the Pd-content. This clearly suggests that the HIC behavior of Ti Grade 7 should be at least as good as that of Ti Grade 16 (i.e. $~ 1000 \mu \mathrm{g} / \mathrm{g}$ ). Ikeda et al. studied the HIC behavior of Ti Grade 16 in comparison with $\mathrm{Ti}$ Grades 2 and $12[103,104]$ and concluded that the much higher $\mathrm{H}_{\mathrm{C}}$ for Ti Grade 16 is due to prevention of hydride formation by the higher solubility of hydrogen in Pd intermetallic particles. The authors stated that intermetallic particles do not act as hydrogen absorption windows but may promote proton discharge favoring hydrogen gas production. 
An experimentally obtained critical hydrogen concentration for Ti Grade 24 is not available at this time. However, an approximate $\mathrm{H}_{\mathrm{C}}$ value of this alloy can be inferred from the corrosion behavior of Ti Grade 5. Testing of Ti Grade 5 and its Pd-modified version, Ti Grade 24, showed that the addition of Pd improves the alloy's corrosion resistance in a manner similar to that observed when Pd is added to the Ti Grade 2 alloy to produce Ti Grade $16[20,27,105]$. For Ti Grade 5, Hardie and Ouyang showed that the fracture toughness was not significantly altered until the hydrogen level in the alloy exceeded $200 \mu \mathrm{g} / \mathrm{g}$ [106]. For smooth tensile specimens, the authors showed that the reduction in area and elongation of Ti Grade 5 did not decrease until the hydrogen concentration reached about 1,500 $\mu \mathrm{g} / \mathrm{g}$ [106]. Addition of Pd to Ti Grade 5 (to produce Ti Grade 24) should lead to a higher value of $\mathrm{H}_{\mathrm{C}}$ as it did for additions of $\mathrm{Pd}$ to Ti Grade 2 (to produce Ti Grades 7 and 16). However, considering the higher strength of Ti Grade 24 compared to Ti Grades 7 and 16, the effect of Pd on $\mathrm{H}_{\mathrm{C}}$ should not be as great. It can be estimated conservatively, based on the above analysis, that the $\mathrm{H}_{\mathrm{C}}$ of $\mathrm{Ti}$ Grade 24 should be at least in the range of $400-600 \mu \mathrm{g} / \mathrm{g}$, if not higher. This estimated value of $\mathrm{H}_{\mathrm{C}}$ is realistic and conservative. For instance, Kitayama et al. [105] evaluated the effect of Pd additions to Ti-6Al-4V (Ti Grade 5) and Ti-3Al-2.5V (Ti Grade 9) on their HIC behavior. By cathodically charging hydrogen to Pd-containing Ti-6Al-4V (an equivalent to $\mathrm{Ti}$ Grade 24) to approximately 1,000 and $1,100 \mathrm{ppm}$, the 0.2 percent proof stress was found to be 
175 and $145 \mathrm{ksi}$, respectively [105], suggesting that no degradation in mechanical properties occurred due to this hydrogen content.

It has also been shown experimentally that $\mathrm{H}_{\mathrm{C}}$ increases markedly with temperature [98]. For Ti Grade 2 although the maximum critical stress intensity factor decreases from $\sim 50 \mathrm{MPa} / \mathrm{m}^{1 / 2}$ at $25^{\circ} \mathrm{C}$ to $\sim 40 \mathrm{MPa} / \mathrm{m}^{1 / 2}$ at $95^{\circ} \mathrm{C}$, at $95^{\circ} \mathrm{C}$ only slow crack growth was observed up to hydrogen concentrations of $\sim 2000$ $\mu \mathrm{g} / \mathrm{g}$, indicating an enhanced resistance to fast brittle fracture as the temperature is increased. A similar increase in resistance to brittle fracture was observed for $\mathrm{Ti}$ Grade 12 at $95^{\circ} \mathrm{C}$, the maximum stress intensity factor decreasing from $\sim 60 \mathrm{MPa} / \mathrm{m}^{1 / 2}$ at $25^{\circ} \mathrm{C}$ to $\sim 45 \mathrm{MPa} / \mathrm{m}^{1 / 2}$, while $\mathrm{H}_{\mathrm{C}}$ increased to $\sim 1000 \mu \mathrm{g} / \mathrm{g}$ [98]. Therefore, it can be assumed that failure is less likely at elevated temperature in part due to higher hydrogen solubility.

\section{Modeling of Drip Shield HIC}

A simple model has been developed to estimate the hydrogen content in titanium alloys due to passive corrosion $[103,104]$ and has been used in several studies on HIC $[107,108]$. In the model, the concentration of hydrogen in the metal, $\mathrm{H}_{\mathrm{A}}$, can be calculated as a function of time and corrosion rate from the expression:

where

$$
H_{A}=4 \times 10^{6} f_{h} R_{u c} t\left[M_{T i}\left(d_{o}-R_{u c} t\right)\right]^{-1}
$$

$$
\begin{aligned}
& \mathrm{H}_{\mathrm{A}}=\text { hydrogen content }(\mu \mathrm{g} / \mathrm{g}) \\
& \mathrm{f}_{\mathrm{h}}=\text { fractional efficiency for hydrogen absorption }=0.015 \\
& R_{u c}=\text { rate of general passive corrosion }(\mathrm{mm} / \text { year })=6.75 \times 10^{-5} \mathrm{~mm} / \text { year } \\
& \mathrm{t}=\text { time in years }
\end{aligned}
$$


$\mathrm{M}_{\mathrm{Ti}}=$ atomic mass of $\mathrm{Ti}=47.9$

$\mathrm{d}_{\mathrm{o}}=$ specimen thickness

Using the maximum general corrosion rate from samples exposed for 5 years in the LTCTF [74], the hydrogen content in a $7.5 \mathrm{~mm}$ thick (half of the drip shield thickness) after 10,000 years can be estimated as:

$$
\mathrm{H}_{\mathrm{A}}=124 \mu \mathrm{g} / \mathrm{g} \ll \mathrm{H}_{\mathrm{C}}=1,000 \mu \mathrm{g} / \mathrm{g}
$$

The fractional hydrogen absorption efficiency $\left(f_{h}\right)$ used in the calculation $(0.015)$ is similar to that obtained experimentally for Ti Grade 2 under an applied current density of $0.5 \mathrm{~mA} / \mathrm{cm}^{2}$ at $25^{\circ} \mathrm{C}$ in sodium sulfate solutions $(\mathrm{pH}=4)$ [45]. The electrode potential during these experiments was $-1.14 \mathrm{~V}_{(\mathrm{SCE})}$, about $-0.5 \mathrm{~V}$ more negative than the threshold value of $-0.6 \mathrm{~V}_{(\mathrm{SCE})}$ for significant hydrogen absorption [45]. This kind of low potential is extremely cathodic and well beyond that achievable by galvanic coupling to less noble metals (e.g., carbon steel). Furthermore, the model does not account for decreases in hydrogen absorption efficiency as the hydrogen content in the metal increases, or removal of hydrogen by removal of material by general corrosion. Therefore, the above calculated 124 $\mu \mathrm{g} / \mathrm{g}$ in 10,000 years represents the worst case scenario where the titanium alloy is galvanically coupled to a less noble metal (unlikely to occur) and no hydrogen removal processes are considered. On this basis, hydrogen embrittlement of the titanium drip shield is unlikely during the regulatory period. 


\section{RADIATION-ASSISTED DEGRADATION}

Studies on Ti Grades 2 and 7 in simulated gamma radiation environments showed no evidence of photo-induced corrosion $[109,110,111]$. Photocorrosion leads to oxide thinning for $\mathrm{pH} \leq 3$ but for $\mathrm{pH}>3$, to the accumulation of an outer layer of hydrated $\mathrm{TiO}_{2}[110,111]$. According to the point defect model [112], thinning of the oxide would lead to an increase in passive corrosion rate.

Photo-induced film growth leads to a decrease in defectiveness of the oxide [113, 114] and photoinhibition of localized corrosion on materials such as $\mathrm{Ni}, \mathrm{Fe}, \mathrm{Cu}$, $\mathrm{Cu}-\mathrm{Ni}$ alloys and stainless steels [112]. Similar improvements in passive film properties were observed on $\mathrm{Ti}$ Grade 12 exposed to gamma radiation in a concentrated brine similar in composition to those anticipated in Yucca Mountain $[64,65]$. These last authors concluded that any photo-effect induced by gamma radiation is likely to be minor compared to the influence of the production of oxidants by water radiolysis. Therefore, the influence of gamma radiation on corrosion processes can be assessed by radiolytic effects only. Glass et al [115, 116], on stainless steels, and Kim and Oriani [64, 65], on Ti Grade 12, have shown that radiolysis can be simulated by adding $\mathrm{H}_{2} \mathrm{O}_{2}$. The observed influences of $\mathrm{H}_{2} \mathrm{O}_{2}$ on the corrosion behavior of titanium are to increase corrosion potential [117] and, if at a sufficient concentration, corrosion rates $[64,65]$, the latter by reduction in the inner barrier layer thickness accompanied by the accumulation of the increased corrosion product in a thicker outer hydrated layer [118]; i.e., an 
effect similar to that observed by UV-irradiation of the passive film $[110,111]$ consistent with the point defect model [112].

In general, no significant influence of gamma radiation was observed on a range of Ti alloys (including Ti Grades 2, 7, and 12) in a wide range of environments for temperatures up to $250^{\circ} \mathrm{C}$ [90]. Consistent with observations made in $\mathrm{H}_{2} \mathrm{O}_{2}$ solutions, some film thickening was observed at higher dose rates $\left(10^{5} \mathrm{Rad} / \mathrm{hour}\right)$ and groundwater species, such as $\mathrm{Mg}^{2+}$, were incorporated into the outer regions of the passive film. This last observation is consistent with the expectations of the point defect model [112].

\section{OTHER CONSIDERATIONS}

\section{Effects of Bromide on Corrosion of Titanium}

A comparison of the pitting potentials measured in $\mathrm{Cl}^{-}$solutions to those measured in $1.0 \mathrm{~mol} / \mathrm{L} \mathrm{Br}^{-}$shows that at high temperatures $\left(\geq 120^{\circ} \mathrm{C}\right)$, pitting potentials in the two electrolytes are not radically different [89]. However, the radical improvement in pitting potential observed for $\mathrm{Cl}^{-}$solutions at lower temperatures are not observed in $\mathrm{Br}^{-}$solutions, pitting potentials in the range of 1 to $2 \mathrm{~V}_{\text {(SCE) }}$ being observed in the temperature range $25^{\circ} \mathrm{C}$ to $120^{\circ} \mathrm{C}$ [89].

A number of authors have attempted to explain why pit initiation occurs in $\mathrm{Br}^{-}$, but not $\mathrm{Cl}^{-}$, solutions $[60,61,119,120,121,122]$. Perhaps surface sites enriched in $\mathrm{Br}^{-}$eventually develop into pits [121] or redox sites form at which pit initiation 
occurs $[119,122]$. Breakdown sites are thought to be associated with impurity inclusions $[123,124,125]$ or with areas where the oxide is thinner and more nonstoichiometric [119]. It can be safely concluded that impurities do not render $\mathrm{Ti}$ susceptible to localized corrosion at the corrosion potentials $\left(-0.3\right.$ to $\left.+0.1 \mathrm{~V}_{(\mathrm{SCE})}\right)$ anticipated in the Yucca Mountain repository, particularly in view of the fact that the effect of $\mathrm{Br}^{-}$becomes less significant in the presence of other anions, especially $\mathrm{Cl}^{-}$and $\mathrm{SO}_{4}{ }^{2-}[119]$.

\section{Microbially Influenced Corrosion}

Microbially influenced corrosion (MIC) is the change in the corrosion rate of an industrial alloy by the presence and activity of microorganisms either due to the direct impact of microorganisms on the anodic or cathodic kinetics of the alloy, or indirectly by chemical effects on the surrounding solution [126]. Corrosion handbooks and literature reviews generally state that titanium alloys are immune to $\mathrm{MIC}[72,127,128]$ due to the stability of the $\mathrm{TiO}_{2}$ passive film. While titanium is susceptible to biofouling in seawater solutions, the biofilm does not compromise the integrity of the passive film and therefore, biofouled titanium maintains its resistance to localized corrosion processes [127]. It has been reported that the production of nitrates, polythionates, thiosulfates, and oxygen associated with aerobic biologic activity does not significantly increase the corrosion rate of $\mathrm{Ti}$ alloys [72]. 
Steep gradients in $\mathrm{O}_{2}$ and $\mathrm{pH}$ can exist within biofilms, which are typically aerobic and near neutral but acidic and low in $\mathrm{O}_{2}$ close to the metal surface [32]. Hydrogen peroxide has been detected in biofilms at millimolar levels [32]. Hydrogen peroxide maintains a low $\mathrm{pH}(<3)$ near the metal by oxidizing metal cations which then undergo hydrolysis. These chemical changes can lead to enoblement (a shift of the corrosion potential to more positive values) of titanium by up to $500 \mathrm{mV}$ [32]. It is clear from Figure 14 that $\Delta E$ far exceeds $500 \mathrm{mV}$ at low $\mathrm{pH}$ values (i.e., localized corrosion will not initiate). Enoblement can also be beneficial by thickening of the passive film and decreasing the number density of defects [32]. According to Shoesmith et al. [101], the initiation of crevice corrosion under biofilms has never been observed for titanium. This can be attributed to the requirement for a temperature $>70^{\circ} \mathrm{C}$ for crevice initiation, at which temperature microbial activity is severely suppressed [129]. Lastly, microbial growth in the proposed repository will likely be limited by the availability of nutrients [130].

\section{Galvanic Coupling to Other Metals}

The coupling of Ti to active metals could cause hydrogen absorption and eventual embrittlement when the temperature is $>80^{\circ} \mathrm{C}$ [52]. The coupling of $\mathrm{Ti}$ to less active materials $[131,132]$ can also lead to the enhanced corrosion of the coupled material. It is unlikely that galvanic corrosion potentials can be sufficiently cathodic to induce significant hydrogen absorption by Ti alloys. 
According to Schutz [133], Ti should generally be the cathode in galvanic couples, but Reclaru and Meyer [134] have shown Ti to be the anode when in contact with a series of dental alloys, although the galvanic currents were extremely low. Wang et al. [44] reported that Ti Grade 2 could form either the anode or cathode when coupled to various materials in hot $\left(50^{\circ} \mathrm{C}\right.$ to $\left.90^{\circ} \mathrm{C}\right) 6 \%$ $\mathrm{NaCl}$. Brass and Alloy 600 anodically polarize Ti, while 316 stainless steel and Monel could polarize $\mathrm{Ti}$ either anodically or cathodically depending on temperature and $\mathrm{pH}$. However, the reliability of these last results is uncertain since it is not clear whether the pretreatment of the specimens used in the experiments caused surface hydriding or not, or whether similarly polarized couples would be obtained for alternative geometries and coupled surface areas.

From this discussion, galvanic couples involving $\mathrm{Ti}$ and other passive materials are unlikely to lead to significant corrosion of either material. The prospect of a galvanic couple between the Ti Grade 7 drip shield and the Alloy 22 waste package leading to any significant damage of either material is remote.

\section{Effects of $\mathrm{CaCl}_{2}$ and $\mathrm{MgCl}_{2}$}

The general corrosion rates of $\mathrm{Ti}$ Grade 7 in $\mathrm{Ca}^{2+}, \mathrm{Fe}^{3+}$ and $\mathrm{Mg}^{2+}$ containing environments at elevated temperatures are generally reported as negligible [52]. Considerable evidence exists to show $\mathrm{Ca}^{2+}$ and/or $\mathrm{Mg}^{2+}$ cations are incorporated into the outer layer of the oxide film. These studies range from those primarily interested in the performance of $\mathrm{Ti}$ as a body-implant material $[117,135,136$, 
137] to those in which Ti was tested for its durability under nuclear waste disposal conditions $[94,138,139]$. The incorporation of $\mathrm{Ca}^{2+} / \mathrm{Mg}^{2+}$ into the outer layers of the passive film is a consequence of the corrosion process not a stimulant for it. A review of corrosion rate measurements made on Ti Grade 2, Ti Grade 12 and $\mathrm{Ti}$ Grade 7 in geothermal brine environments containing up to $28,800 \mathrm{mg} / \mathrm{L}$ of $\mathrm{Ca}^{2+}$ in $155,000 \mathrm{mg} / \mathrm{L}$ of $\mathrm{Cl}^{-}$gave values of $<1 \mu \mathrm{m} / \mathrm{yr}$ at $232^{\circ} \mathrm{C}$ [140]. No evidence for pitting or crevice corrosion of Ti Grade 7 was seen [93]. Schutz and Grauman [141] reported no crevice corrosion on Ti Grade 7 in up to $44 \% \mathrm{MgCl}_{2}$ at $260^{\circ} \mathrm{C}$, and for $50 \% \mathrm{MgCl}_{2}$ up to nearly $200^{\circ} \mathrm{C}$. Similar observations were reported by Satoh et al. [24] who found no sign of crevice corrosion on Ti Grade 7 in boiling $42 \% \mathrm{MgCl}_{2}$.

\section{CONCLUDING REMARKS}

The metallurgy of titanium alloys was reviewed with particular emphasis on $\mathrm{Ti}$ Grades 7 and 24 (the materials used in fabrication of the drip shields). It was concluded that aging and phase instability will have an insignificant effect on drip shield performance in the repository. The effect of alloying elements, particularly the platinum group metals such as Pd, on degradation of Ti alloys was reviewed. There is strong evidence that Pd accumulates on the surface of Ti-Pd alloys during corrosion in acidic solutions. Pd can act as a catalyst for proton reduction leading to the possibility of enhancement of hydrogen absorption. The effects of $\mathrm{Ni}$ and Fe additions on hydrogen absorption were also reviewed. 
The properties of the passive film formed on Ti alloys were reviewed. Anodic polarization leads to oxide thickening and a decrease in the number density of defects. In the temperature range of $50^{\circ} \mathrm{C}$ to $70^{\circ} \mathrm{C}$, a breakdown/recrystallization process to yield anatase/rutile occurs accompanied by the absorption of water, which generally leads to an improvement in passivity. Defective surface oxide films can enhance hydrogen absorption and corrosion in fluoride-containing solutions.

General corrosion, localized corrosion (crevice corrosion and pitting), stress corrosion cracking (SCC), and hydrogen induced cracking (HIC) were reviewed for the relevant titanium alloys ( $\mathrm{Ti}$ Grades 7,12 , and 16) under repository exposure conditions. General corrosion rates calculated from weight-loss data of Ti Grade 16 exposed for up to 5 years in repository relevant environments were found to be very low. It was found that the crevice corrosion resistance of Ti alloys improves according to the sequence Ti Grade $2 \ll$ Ti Grade $12<$ Ti Grade 16 , and the crevice propagation rate and extent decreased by orders of magnitude through this series. Pitting potentials at room temperature for $\mathrm{Ti}$ alloys are in excess of $7 \mathrm{~V}$, and even for temperatures greater than $150^{\circ} \mathrm{C}$ are in the region of $2 \mathrm{~V}$. Both pitting and crevice corrosion can be considered extremely remote possibilities under Yucca Mountain conditions.

Most titanium alloys, including Grades 2, 7, and 12, exhibit high resistance to SCC in a variety of exposure environments regardless of applied stress, 
metallurgical condition, or exposure temperature. However, Ti Grade 7 has been observed to undergo SCC in tests in concentrated repository relevant solutions. It is hypothesized that difficulties associated with initiating SCC in $\mathrm{Ti}$ alloys (e.g., pre-cracking must be initiated in the testing solution) and the ease with which they repassivate may account for SCC being rarely observed.

Titanium and its alloys may be susceptible to HIC when the exposure temperature exceeds $80^{\circ} \mathrm{C}$ and the $\mathrm{pH}$ is below 3 or above 12 . However, HIC will not occur until the hydrogen concentration in the metal reaches a threshold value $\left(\mathrm{H}_{\mathrm{C}}\right)$. At room temperature, $\mathrm{H}_{\mathrm{C}}$ values of 500 to $800 \mu \mathrm{g} / \mathrm{g}$ (Ti Grade 2), 400 to $600 \mu \mathrm{g} / \mathrm{g}$ (Ti Grade 12), and 1000 to $2000 \mu \mathrm{g} / \mathrm{g}$ (Ti Grade 16) have been determined. It was shown that $\mathrm{H}_{\mathrm{C}}$ rises markedly with temperature. The increase in $\mathrm{H}_{\mathrm{C}}$ of $\mathrm{Ti}$ Grade 16 over Ti Grades 2 and 12 is most likely due to the addition of palladium.

Gamma radiation could influence the corrosion of passive materials such as $\mathrm{Ti}$ Grade 7 by photocorrosion and/or water radiolysis. Studies on Ti Grade 2 and Grade 7 in simulated gamma radiation environments showed no evidence of photocorrosion. No significant influence of water radiolysis due to gamma radiation has been observed on a range of Ti alloys (including Ti Grades 2, 7, and 12) studied in a wide range of environments (including aggressive $\mathrm{Mg}$-containing brines) for temperatures up to $250^{\circ} \mathrm{C}$. In fact, gamma radiation was shown to reduce the number of defects in the oxide and to inhibit hydrogen absorption. 
The effects of fluoride, bromide, and divalent chloride salts were summarized. The presence of dissolved fluoride in brine solutions can significantly increase the general corrosion rate of titanium alloys with defective oxide films. However, if the passive film has a sufficiently low defect density, fluoride ions have little effect. While bromide ions do have a significant effect on the repassivation potentials of $\mathrm{Ti}$ alloys at high temperatures, their presence will not render $\mathrm{Ti}$ Grade 7 susceptible to localized corrosion under repository exposure conditions. The influence of $\mathrm{Br}^{-}$is further suppressed when other ions such as $\mathrm{Cl}^{-}$and $\mathrm{SO}_{4}{ }^{2-}$ are present. The effects of divalent chloride salts on the general corrosion characteristics of Ti alloys was found to be insignificant.

Finally microbially influenced corrosion (MIC) of Ti alloys was reviewed. It was concluded that although biofouling has been observed on Ti alloys, the biofilm does not compromise the integrity of the passive film and or its resistance to localized breakdown. The formation of hydrogen peroxide from biogenic activity would lead to several beneficial effects including thickening of the passive film and a decrease in the number density of defects.

\section{ACKNOWLEDGEMENTS}

This work was performed and funded under DOE contract DE-AC0801RW12101 for the Civilian Radioactive Waste Management System (CRWMS M\&O) led by the prime contractor Bechtel SAIC Company, LLC. The authors are in debt to Raul Rebak, Lana Wong and other LLNL investigators for their 
permission of using the general and localized corrosion data obtained at LLNL in this paper. The authors also thank Tammy Summers and David Stahl for their technical review of the manuscript.

\section{REFERENCES}

[1] Act. Nuclear Waste Policy Amendments Act of 1987. Public Law No. 100-203, 101 Stat. 1330 (1987)

[2] CRWMS M\&O. “Waste Package Degradation Process Model Report." TDR-WIS-MD000002 REV 00 ICN 02. (2000)

[3] DOE (U.S. Department of Energy). Yucca Mountain Science and Engineering Report. DOE/RW-0539, Rev. 1. (2002)

[4] Farmer, J., McCright, D., Gdowski, G., Wang, F., Summers, T., Bedrossian, P., Horn, J., Lian, Y., Estill, J., Lingenfelter, A., and Halsey, W., "General and Localized Corrosion of Outer Barrier of High-Level Waste Container in Yucca Mountain," Proceeding of ASME/PVP Conference, American Society of Mechanical Engineers, Seattle, Washington, July 23-27, 2000. (2000)

[5] Andresen, P.L., Emigh, P.W., Young L.M., and Gordon G.M., "Stress Corrosion Cracking of Annealed and Cold Worked Titanium Grade 7 and Alloy 22 in $110^{\circ} \mathrm{C}$ Concentrated Salt Environments," Corrosion 2001, Paper No. 01130, NACE. (2001)

[6] Dunn, D.S., Pan Y.M., and Cragnolino, G.A., "Stress Corrosion Cracking, Passive, and Localized Corrosion of Alloy 22 High Level Radioactive Waste Containers." Corrosion 2000, Paper No. 00206 (2000)

[ 7] Roy, A. and Flemming, D., "Galvanic Corrosion Study of Container Materials Using Zero Resistance Ammeter." Corrosion 1998, Paper No. 156 (1998)

[8] Roy, A. and Flemming, D., "Galvanic Corrosion - Effect of Environmental and Experimental Variables," Corrosion 1999, Paper No. 465 (1999)

[9] Lian, T., Martin, S., Jones, D., Rivera, A., and Horn, J., "Corrosion of Candidate Container Materials by Yucca Mountain Bacteria." Corrosion 1999, Paper No. 476 (1999)

[10] Horn, J., Martin, S., Masterson, B., and Lian, T., "Biochemical Contributions to Corrosion of Carbon Steel and Alloy 22 in a Continual Flow System." Corrosion 1999, Paper No. 162 (1999).

[11] Horn, J., Martin, S., Rivera, A., Bedrossian, P., and Lian, T., "Potential Biogenic Corrosion of Alloy 22, A Candidate Nuclear Waste Rackaging Material, Under Simulated Repository Conditions," Corrosion 2000, Paper No. 00387 (2000).

[12] Hua, F., Sarver, J., Jevec, J. and Gordon, G., "General Corrosion Studies of Candidate Container Materials in Environments Relevant to Nuclear Waste Repository." Corrosion/2002, [57th Annual Conference \& Exposition, April 7-11, 2002, Denver, Colorado]. Paper No. 02530. (2002).

[13] Hua, F. and Gordon, G., "On Apparent Bi-Linear Corrosion Rate Behavior of Ti Grade 7 in Basic Saturated Water (BSW-12) Below and Above 80 ${ }^{\circ}$." Corrosion 2003, Paper No. 03687 (2003).

[14] NWTRB, International Workshop on Long-Term Extrapolation of Passive Behavior, US Nuclear Waste Technical Review Board, Arlington, VA, July 19-20, 2001.

[15] Gdowski, G.E., "Degradation Mode Survey Candidate Titanium - Base Alloys for Yucca Mountain Project Waste Package Materials." UCRL-ID-121191, Rev. 1 (1997). 
[16] ASTM B 265-02, "Standard Specification for Titanium and Titanium Alloy Strip, Sheet, and Plate." Philadelphia, Pennsylvania: American Society for Testing and Materials, 2002.

[17] Paton, N.E. and Williams, J.C., "Effect of Hydrogen on Titanium and Its Alloys", in Hydrogen in Metals, Bernstein, I. M. and Tompson, A. W. eds., American Society for Metals, 409-431 (1974).

[18] Shih, D.S., Robertson, I. M, and Brinbaum, Acta Metallurgica, 36 (1), 111 (1988).

[19] Moody, N.R. and Costa, N.R., "A Review of Microstructure Effects on Hydrogen-Induced Sustained Load Cracking in Structural Alloys," in Microstructure/Property Relationships in Titanium Aluminides and Alloys, Kim, Y.-W and Boyer, R. R. (eds), 587-604 (1991)

[20] Schutz, R.W., "Recent Titanium Alloy and Product Developments for Corrosive Industrial Service." Corrosion 95, Paper No. 244, 244/1-244/20 (1995).

[21] R. W. Schutz, "Platinum Group Metal Additions to Titanium: A Highly Effective Strategy for Enhancing Corrosion Resistance", Corrosion, 59, pp. 1043-1057 (2003).

[22] Uhlig, H.H., The Corrosion Handbook. 1144-1145 (1948).

[23] Cotton, J.B., "The Role of Palladium in Enhancing Corrosion Resistance of Titanium." Platinum Metals Review, 11 (2), 50-52 (1967).

[24] Satoh, K., Shimogori, K., and Kamikubo, F. , "The Crevice Corrosion Resistance of Some Titanium Materials: A Review of the Beneficial Effects of Palladium." Platinum Metals Review, 31, (3), 115-121 (1987).

[25] Sedriks, A.J., "Corrosion Resistance of Titanium-Ruthenium Alloys." Corrosion, 31 (2), 60 65 (1975).

[26] Hall, J.A., Banerjee, D., and Wardlaw, T.L., "The Relationships of Structure and Corrosion Behavior of Ti-0.3Mo-0.8Ni (TiCode-12)." Titanium, Science and Technology: Proceedings of the Fifth International Conference on Titanium, Munich, Germany, September 10-14, 1984. Lutjering, G., Zwicker, U., and Bunk, W., eds. 4, 2603-2610 (1985).

[27] Schutz, R.W. and Xiao, M., "Optimized Lean-Pd Titanium Alloys for Aggressive Reducing Acid and Halide Service Environments." Corrosion Control for Low-Cost Reliability, Proceedings, 12th International Corrosion Congress, [Houston, Texas, September 19-24, 1993]. $3 \mathrm{~A}, 1213-1225$ (1993).

[28] McKay, P., "Crevice-Corrosion Kinetics on Titanium and a Ti-Ni-Mo Alloy in Chloride Solutions at Elevated Temperature." Corrosion Chemistry Within Pits, Crevices, and Cracks, Proceedings of a Conference held at Teddington, Middlesex, October 1-3, 1984. Turnbull, A., ed. Paper 7, 107-128 (1987).

[29] Van der Lingen, E. and de Villiers Steyn, H., "The Potential of Ruthenium as an Alloying Element in Titanium." Titanium 1994, Products and Applications, Proceedings of the Technical Program from the 1994 International Conference. Pages 450-461 (1994).

[30] Glass, R.S., "Effect of Intermetallic $\mathrm{Ti}_{2} \mathrm{Ni}$ on the Electrochemistry of TiCode-12 in Hydrochloric Acid." Electrochimica Acta, 28, (11), 1507-1513 (1983).

[31] Kidoh, T. and Tsujikawa, S., "Effects of Ni and Mo on Critical Conditions for Crevice Corrosion of Low Alloy Titanium." Journal of Iron and Steel Institute of Japan, 75 (8), 96-101 (1989).

[32] Shoesmith, D.W. and Ikeda, B.M., "The Resistance of Titanium to Pitting, Microbially Induced Corrosion and Corrosion Under Unsaturated Conditions." Atomic Energy of Canada Limited Report, AECL-11709, COG-96-557-I (1997).

[33] Hubler, G.K. and McCafferty, E., "The Corrosion Behaviour and Rutherford Back-Scattering Analysis of Palladium-Implanted Titanium." Corrosion Science, 20, 103-116 (1980).

[34] Armstrong, R.D., Firman, R.E., and Thirsk, H.R., "Ring-Disc Studies of Titanium-Palladium Alloy Corrosion." Corrosion Science, 13, 409-420. (New York, New York): Pergamon Press (1973). 
[35] Murai T., Ishikawa, M., and Miura, C., "The Absorption of Hydrogen into Titanium Under Cathodic Polarization." Corrosion Engineering, 26 (4), 177-183 (1977).

[36] Greef, R., Peat, R., Peter, L.M., Pletcher, D. and Robinson, J., "Electrocatalysis." Chapter 7 of Instrumental Methods in Electrochemistry (1985).

[37] Shoesmith, D.W., Hocking, W.H., Ikeda, B.M., King, F., Noël, J.J., and Sunder, S., "Application of Electrochemical Methods in the Development of Models for Fuel Dissolution and Container Corrosion Under Nuclear Waste Disposal Conditions." Canadian Journal of Chemistry, 75 (11), 1566-1584 (1997).

[38] Noël, J.J., "The Electrochemistry of Titanium Corrosion." Ph.D. Dissertation. Winnipeg, Manitoba, Canada: University of Manitoba (1999).

[39] Ikeda, B.M. and Quinn, M.J. "Hydrogen Assisted Cracking of Grade-16 Titanium: A Preliminary Examination of Behaviour at Room Temperature." 06819-REP-01200-0039 R00. Toronto, Ontario, Canada: Ontario Hydro (1998).

[40] Ikeda, B.M. and Quinn, M.J. "A Preliminary Examination of the Effects of Hydrogen on the Behaviour of Grade-16 Titanium at Room Temperature." 06819-REP-01200-0078-R00. Toronto, Ontario, Canada: Ontario Hydro (1998).

[41] Takekawa, T., Data for Japanese Society of Titanium, Oct. 15th, 1973.

[42] Fukuzuka, T., Shimogori, K. and Satoh, H. "Role of Palladium in Hydrogen Absorption of TiPd Alloy." Titanium '80, Science and Technology: Proceedings of the Fourth International Conference on Titanium, Kyoto, Japan, May 19-20, 1980.

[43] Takamura, A. and Yamagata, T., "Titanium, Zirconium." 15 (8), 192 (1967).

[44] Wang, Z.W., Briant, C.L., and Kumar, K.S., "Electrochemical, Galvanic, and Mechanical Responses of Grade 2 Titanium in 6\% Sodium Chloride Solution." Corrosion, 55, (2), 128-138 (1999).

[45] Okada, T., "Factors Influencing the Cathodic Charging Efficiency of Hydrogen by Modified Titanium Electrodes." Electrochimica Acta, 28, (8), 1113-1120 (1983).

[46] CRWMS M\&O, "Environment on the Surfaces of the Drip Shield and Waste Package Outer Barrier." ANL-EBS-MD-000001 REV 00 (2000).

[47] Watanabe, T., Shindo, T. and Naito, H., "Effect of Iron Content on the Breakdown Potential for Pitting of Titanium in $\mathrm{NaCl}$ Solutions." Sixth World Conference on Titanium: Cannes, June 69, 1988. Lacombe, P., Tricot, R., and Beranger, G., eds. IV, 1735-1740 (1988).

[48] Cotton, J.B. 1970. "Using Titanium in the Chemical Plant." Chemical Engineering Progress, $66,(10), 57-62(1970)$.

[49] Covington, L.C. and Schutz, R.W., "Effects of Iron on the Corrosion Resistance of Titanium." Industrial Applications of Titanium and Zirconium, A Symposium held in New Orleans, Louisiana, 15-17 October, 1979. Kleefisch, E.W., ed. ASTM Special Technical Publication 728, 163-180 (1981).

[50] Schutz, R.W., Grauman, J.S., and Hall, J.A., "Effect of Solid Solution Iron on the Corrosion Behaviour of Titanium." Titanium, Science and Technology: Proceedings of the Fifth International Conference on Titanium, Congress-Center, Munich, FRG, September 10-14, 1984. Lutjering, G., Zwickler, U., and Bunk, W., eds. 4, 2617-2624 (1985).

[51] Wu, J.B.C., "Effect of Iron Content on Hydrogen Absorption and Passivity Breakdown of Commercially Pure Titanium in Aqueous Solutions." Titanium, Science and Technology, Proceedings of the Fifth International Conference on Titanium, Congress-Center, Munich, FRG, September 10-14, 1984. Lutjering, G., Zwickler, U., and Bunk, W., eds. 4, 2595-2602 (1985).

[52] Schutz, R.W. and Thomas, D.E., "Corrosion of Titanium and Titanium Alloys." In Corrosion, Volume 13, 669-706 of ASM Handbook (1987).

[53] Kudelka, S., Michaelis, A., and Schultze, J.W., "Electrochemical Characterization of Oxide Layers on Single Grains of a Polycrystalline Ti-Sample." Berichte der Bunsen-Gesellschaft fur 
Physikalische Chemie (An International Journal of Physical Chemistry), 99, (8), 1020-1027. Deerfield Beach, Florida: VCH Publishers. (1995).

[54] Shibata, T. and Zhu, Y.-C., "The Effect of Film Formation Conditions on the Structure and Composition of Anodic Oxide Films on Titanium." Corrosion Science, 37, (2), 253-270 (1995).

[55] Shibata, T. and Zhu, Y.-C., "The Effect of Film Formation Temperature on the Stochastic Processes of Pit Generation on Anodized Titanium." Corrosion Science, 36 (10), 1735-1749 (1994).

[56] Kelly, E.J., "Anodic Dissolution and Passivation of Titanium in Acidic Media. III. Chloride Solutions." Journal of the Electrochemical Society, 126 (12), 2064-2075 (1979).

[57] Watanabe, T., Kondo, M., Naito, H., and Sakai., K., "Electrochemical Properties and Corrosion Characteristics of Titanium in Chloride Solutions. "Nippon Steel Technical Report No. 39, 40. 29-35. Chiyoda-ku, Tokyo, Japan: Nippon Steel Corporation (1989).

[58] Blackwood, D.J., Peter, L.M., and Williams, D.E., "Stability and Open Circuit Breakdown of the Passive Oxide Film on Titanium." Electrochimica Acta, 33, (8), 1143-1149 (1988).

[59] Ohtsuka, T., Masuda, M., and Sato, N., "Cathodic Reduction of Anodic Oxide Films Formed on Titanium." Journal of Electrochemical Society, 134 (10), 2406-2410 (1987).

[60] Beck,T.R., "Pitting of Titanium. I. Titanium Foil Experiments." Journal of the Electrochemical Society, 120,1317-1316 (1973).

[61] Beck, T.R., "Pitting of Titanium. II. One-Dimensional Pit Experiments." Journal of the Electrochemical Society, 120, 1317-1324 (1973).

[62] Pyun, S-I and Yoon, Y-G 1996. "Hydrogen Transport Through TiO2 Film Prepared by Plasma Enhanced Chemical Vapour Deposition (PECVD) Method." Hydrogen Effects in Materials, Proceedings of the Fifth International Conference on the Effect of Hydrogen on the Behavior of Materials, Moran, Wyoming, September 11-14, 1994. Thompson, A.W. and Moody, N.R., eds., 261-269 (1996).

[63] Tomari, H., Masugata, T., Shimogori, K., Nishimura, T., Wada, R., Honda, A., and Taniguchi, N., "Hydrogen Absorption of Titanium for Nuclear Waste Container in Reducing Condition. "Zairyo-to-Kankyo, 48, 807-814 (1999).

[64] Kim, Y.J. and Oriani, R.A., "Brine Radiolysis and its Effect on the Corrosion of Grade-12 Titanium." Corrosion, 43, 92-97 (1987).

[65] Kim, Y.J. and Oriani, R.A., "Corrosion Properties of the Oxide Film Formed on Grade-12 Titanium in Brine Under Gamma Radiation." Corrosion, 43, 85-91 (1987).

[66] Covington, L.C., "The Influence of Surface Condition and Environment on the Hydriding of Titanium." Corrosion, 35 (8), 378-382 (1979).

[67] Shimogori, K., Satoh, H., and Kamikubo, F., "Investigation of Hydrogen AbsorptionEmbrittlement of Titanium Used in the Actual Equipment." Titanium, Science and Technology, Proceedings of the Fifth International Conference on Titanium, Congress-Center, Munich, FRG, September 10-14, 1984. Lütjering, G, Zwicker, U., and Bunk, W., eds. 2, 1111-1118 (1985).

[68] Mandry, M.J. and Rosenblatt, G., "The Effect of Fluoride Ion on the Anodic Behavior of Titanium in Sulfuric Acid." Journal of the Electrochemical Society, 119, (1), 29-33 (1972).

[69] Wilhelmsen, W. and Grande, A.P., "The Influence of Hydrofluoric Acid and Fluoride Ion on the Corrosion and Passive Behaviour of Titanium." Electrochimica Acta, 32 (10), 1469-1474 (1987).

[70] Nakagawa, M., Matsuya, S., Shiraishi, T., and Ohta, M., "Effect of Fluoride Concentration and pH on Corrosion Behavior of Titanium for Dental Use." Journal of Dental Research, 78 (9), 1568-1572 (1999).

[71] Nakagawa, M., Matsuya, S., and Udoh, K., "Corrosion Behavior of Pure Titanium and Titanium Alloys in Fluoride-Containing Solutions." Dental Materials Journal, 20 (4), 305-314 (2001). 
[72] Brossia, C.S., Browning, L., Dunn, D.S., Moghissi, O.C., Pensado, O., and Yang, L., "Effect of Environment on the Corrosion of Waste Package and Drip Shield Materials. "CNWRA 2001003. San Antonio, Texas: Center for Nuclear Waste Regulatory Analyses (2001).

[73] Lorenzo de Melo, M.F. and Cortizo, M.C., "Electrochemical Behaviour of Titanium in Fluoride-Containing Saliva." Journal of Applied Electrochemistry, 30, ([1]), 95-100 (2000).

[74] BSC (Bechtel SAIC Company), "General Corrosion and Localized Corrosion of the Drip Shield." ANL-EBS-MD-000004 REV 01. Las Vegas, Nevada: Bechtel SAIC Company (2003).

[75] Pan, J., Leygraf, C., Thierry, D., and Ektessabi, A.M., "Corrosion Resistance for Biomaterial Applications of $\mathrm{TiO}_{2}$ Films Deposited on Titanium and Stainless Steel by Ion-Beam-Assisted Sputtering." Journal of Biomedical Materials Research, 35, 309-318 (1997).

[76] Choi, Y-K., Seo, S-S., Chjo, K-H., Choi, Q-W., and Park, S-M., "Thin Titanium Dioxide Film Electrodes Prepared by Thermal Oxidation." J. Electrochem. Soc., 139, (7), 1803-1807 (1992).

[77] Hurlen, T. and Hornkøl, S., "Anodic Growth of Passive Films on Titanium." Electrochimica Acta, 36, (1), 189-195. [New York, New York]: Pergamon (1990).

[78] Kofstad, P., "High Temperature Corrosion." Elsevier Applied Science, London, UK (1988).

[79] Mattsson, H. and Olefjord, I., "ESCA Investigation of the Reaction Products Formed on Titanium Exposed to Water Saturated Bentonite Clay." Scientific Basis for Nuclear Waste Management IX, Materials Research Society Symposium Proceedings, 50, 483-490 (1985).

[80] Mattsson, H. and Olefjord, I., "Analysis of Oxide Formed on Ti During Exposure in Bentonite Clay-I. The Oxide Growth." Werkstoffe und Corrosion, 41, (7), 383-390 (1990).

[81] Mattsson, H., Li, C., and Olefjord, I., "Analysis of Oxide Formed on Ti During Exposure in Bentonite Clay - II. The Structure of the Oxide." Werkstoffe und Korrosion, 41, (10), 578-584 (1990).

[82]Debruyn, W., Dresselears, J., Vermeiren, P., Kelchtermans, J., and Tas, H., "Corrosion of Container and Infrastructure Materials Under Clay Repository Conditions, Task 3 Characterization of Radioactive Waste Forms, A Series of Final Reports (1985-89) No. 28." EUR 13667 EN. Luxembourg, Luxembourg: Commission of the European Communities (1991).

[83] Estill, J.C., "Long-Term Corrosion Studies." 2.2 of Engineered Materials Characterization Report. McCright, R.D., ed. UCRL-ID-1 19564 Volume 3 Rev.1.1 (1998).

[84] Wong, L. L., Estill, J. C., Fix, D. V. and Rebak, R. B. 2003, "Corrosion Characteristics of Titanium Alloys in Multi-ionic Environments", ASME-PVP- Vol. 467 "Transportation, Storage and Disposal of Radioactive Materials" - 2003, page 63, The American Society of Mechanical Engineers, NY (2003).

[85] Schutz, R.W., "Titanium Alloy Crevice Corrosion: Influencing Factors and Methods of Prevention." Proceedings of the Sixth World Conference on Titanium, Cannes, June 6-9, 1988. Lacombe, P., Tricot, R., and Beranger, G., eds. IV, 1917-1922 (1988).

[86] Schutz, R.W., "Ruthenium Enhanced Titanium Alloys: Minor Ruthenium Additions Produce Cost Effective Corrosion Resistant Commercial Titanium Alloys." Platinum Metals Review, 40, (2), 54-61 (1996).

[87] Shoesmith, D.W., King, F., and Ikeda, B.M., "An Assessment of the Feasibility of Indefinite Containment of Canadian Nuclear Fuel Wastes." AECL-10972. Pinawa, Manitoba, Canada: Atomic Energy of Canada Limited (1995).

[88] Posey, F.A. and Bohlmann, E.G., "Pitting of Titanium Alloys in Saline Waters." Desalination, $3(1), 269-279$ (1967).

[89] Koizumi,T. and Furuya., S., "Pitting Corrosion of Titanium in High Temperature Halide Solution." Proceedings of the Second International Conference: Titanium Science and Technology (R.I.Jaffe and H,M, Burte, editors), Plenum Press, New York, NY, 2383-2393 (1973). 
[90] Shoesmith, D.W. and King, F., "The Effects of Gamma Radiation on the Corrosion of Candidate Materials for the Fabrication of Nuclear Waste Packages". AECL-11999. Pinawa, Manitoba, Canada: Atomic Energy of Canada Limited (1999).

[91] Noël, J.J., Shoesmith, D.W., and Ikeda, B.M., "Crevice Corrosion of Alpha Titanium Alloys." Corrosion 2001 Research Topical Symposium, 65-102 (2001).

[92] ASTM G 5-94. (Reapproved 1997), "Standard Reference Test Method for Making Potentiostatic and Potentiodynamic Anodic Polarization Measurements." Philadelphia, Pennsylvania: American Society for Testing and Materials (1997).

[93] Schutz, R.W., "Performance and Application of Titanium Alloys in Geothermal Brine Service." Materials Performance, 39-47 (1985).

[94] Smailos, E. and Köster, R., "Corrosion Studies on Selected Packaging Materials for Disposal of High Level Wastes, in Materials Reliability in the Back End of the Nuclear Fuel Cycle." Proceedings of a Technical Committee Meeting of the International Atomic Energy Agency (IAEA), Vienna, Austria, September 2-5, 1986, IAEA-TECDOC-421 (1987).

[95] Gordon, G.M., "F.N. Speller Award Lecture: Corrosion Considerations Related to Permanent Disposal of High-Level Radioactive Waste." Corrosion, 58 (10), $811-825$ (2002).

[96] Andresen, P.L., Young, L.M., Kim, Y.J., Emigh, P.W., Catlin, G.M., and Martiniano, P.J., "Stress Corrosion Crack Initiation \& Growth Measurements in Environments Relevant to High Level Nuclear Waste Packages." [Schenectady, New York]: GE Global Research Center (2002).

[97] Mountford, Jr., J. A. "Titanium - Properties, Advantages and Applications Solving the Corrosion Problems in Marine Service." Corrosion 2002, Paper No. 02170 (2002).

[98] Clarke, C.F., Hardie, D., and Ikeda, B.M., "Hydrogen Induced Cracking of Grade-2 Titanium." AECL-11284. Pinawa, Manitoba, Canada: Whiteshell Laboratories (1995).

[99] Clarke, C.F., Hardie, D., and Ikeda, B.M., "Hydrogen-Induced Cracking of Commercial Purity Titanium." Corrosion Science, 39 (9), 1545-1559 (1997).

[100] Sorensen, N.R., "Laboratory Studies of the Corrosion and Mechanical Properties of Titanium Grade-12 Under WIPP Repository Conditions." Corrosion of Nuclear Fuel Waste Containers, Proceedings of a Workshop. Winnipeg, Manitoba, 1988 February 9-10. Shoesmith, D.W., ed. AECL-10121, 29-44. Winnipeg, Manitoba, Canada: Atomic Energy of Canada Limited (1990).

[101] Shoesmith, D.W., Ikeda, B.M., Bailey, M.G., Quinn, M.J., and LeNeveu, D.M., "A Model for Predicting the Lifetimes of Grade-2 Titanium Nuclear Waste Containers." AECL-10973. Pinawa, Manitoba,Canada: Atomic Energy of Canada Limited (1995).

[102] Clarke, C.F., Hardie, D., and Ikeda, B.M., "The Effect of Hydrogen Content on the Fracture of Pre-Cracked Titanium Specimens." Corrosion Science, 36, (3), 487-509 (1994).

[103] Shoesmith, D.W., Hardie, D., Ikeda, B.M., and Noel, J.J., "Hydrogen Absorption and the Lifetime Performance of Titanium Waste Containers. " AECL-11770. Pinawa, Manitoba, Canada: Atomic Energy of Canada Limited (1997).

[104] Ikeda, B.M., Quinn, M.J., Noël, J.J., and Shoesmith, D.W., "The Hydrogen-Induced Cracking and Hydrogen Absorption Behaviour of Grade-16 Titanium." Environmentally Induced Cracking of Metals, Proceedings of the International Symposium, August 20-23, 2000, Ottawa, Ontario, Canada. Elboujdaini, M., Ghali, E. and Zheng, W., eds., 235-248 (2000).

[105] Kitayama, S., Shida, Y., Ueda, M., and Kudo, T., "Effect of Small Pd Addition on the Corrosion Resistance of TI and TI Alloys in Severe Gas and Oil Environment." [Techniques for Corrosion Measurement, Papers Presented at the Corrosion/92 Symposium]. Paper No. 52 (1992). [106] Hardie, D. and Ouyang, S., "Effect of Hydrogen and Strain Rate Upon the Ductility of MillAnnealed Ti6A14V." Corrosion Science, 41 (1), 155-177 (1999).

[107]BSC, "Hydrogen Induced Cracking of Drip Shield." ANL-EBS-MD-000006 REV 01. Las Vegas, Nevada: Bechtel SAIC Company (2003). 
[108] Greene, C.A., Henry, A.J., Brossia, C.S., and Ahn, T.M., "Evaluation of the Possible Susceptibility of Titanium Grade 7 to Hydrogen Embrittlement in a Geologic Repository Environment", Mat. Res. Soc. Symp. Proc. 663 (2001).

[109] Michaelis, A., Kudelka, S., and Schultze, J.W., "Effect of Gamma Radiation on the Passive Layers of Ti and Ti-0.2 Pd Container Materials for High-Level Disposal." Electrochimica Acta, 43, 119-130 (1998).

[110] Ohtsuka, T. and Ohtsuki, T., "Effect of Ultra-Violet Light Irradiation on Anodic Oxide Films on Titanium in Sulphuric Acid." J. Electroanal. Chem., 473, 272-278 (1999).

[111] Ohtsuka, T. and T. Ohtsuki., "UV Light-Induced Change of Anodic Oxide Films on Titanium in Acidic Solution." in Passivity and Localized Corrosion, Electrochemical Society Proceedings. Vol. 99-27, edited by M. Seo, B. MacDougall, H. Takahashi and R.G. Kelly, 330-336 (1999).

[112] Macdonald, D.D., "Passivity - The Key to Our Metals-Based Civilization, Pure and Applied Chemistry." 71, 951-78 (1999).

[113] Schmuki, P. and H. Bohni., "Illumination Effects on the Stability of the Passive Film on Iron." Electrochimica Acta, 40, 775-783 (1995).

[114] Sikora, E., Breslin, C., Sikora, J., and Macdonald, D.D., "Semiconductive Properties of Passive Films on Types 304 and 316 Stainless Steel Formed Under UV-Radiation." in Critical Factors in Localized Corrosion II, edited by P.M. Natishan, R.G. Kelly, G.S. Frankel and R.C. Newman, Electrochemical Society Proceedings, 95-15, 341-354 (1995).

[115] Glass, R.S., Van Konynenburg, R.A., and Overturf, G.E., "Corrosion Processes of Austenitic Stainless Steels and Copper-Based Materials in Gamma-Irradiated Aqueous Environments." Corrosion 86, NACE International, Houston, TX, Paper 258 (1986).

[116] Glass, R.S., Overturf, G.E., Van Konynenburg, R.A., and McCright, R.D., "Gamma Radiation Effects on Corrosion -I. Electrochemical Mechanisms for the Aqueous Corrosion Processes of Austenitic Stainless Steels Relevant to Nuclear Waste Disposal In Tuff." Corrosion Science, 26, 577-590 (1986).

[117] Pan, J., Thierry, D., and Leygraf, C., "Electrochemical and XPS Studies of Titanium for Biomaterial Applications With Respect to the Effect of Hydrogen Peroxide." J. Biomedical Materials Research, 28, 113-122 (1994).

[118] Pan, J., Thierry, D., and Leygraf, C.,. "Hydrogen Peroxide Toward Enhanced Growth on Titanium In PBS Solution: Blue Coloration and Clinical Relevance." J. Biomedical Materials Research, 30, 393-402 (1996).

[119] Basame, S.B. and White, H.S., "Pitting Corrosion of Titanium. The Relationship Between Pitting Potential and Competitive Anion Adsorption at the Oxide Film/Electrolyte Interface." J. Electrochem. Soc. 147, 1376-1381 (2000).

[120] Raetzer-Scheibe, H-J., "The Relationship Between Repassivation Behaviour and Pitting Corrosion for Ti and Ti6Al4V." Corrosion, 34, 437-442 (1978).

[121] Petit, J.A., Kondro, B., and Dabosi, F., "Ion Beam Analysis Investigation of Pit Nucleation on Titanium in Bromide Media." Corrosion, 36, 145-151 (1980).

[122] Casillas, N., Charlebois, S., Smyrl W.H., and White. H.S., "Pitting Corrosion of Titanium." Journal of the Electrochemical Society, 141, 636-642 (1994).

[123] Garfias-Mesias, L.F., Alodan, M., James, P.I., and Smyrl, W.H., "Determination of Precursor Sites for Pitting Corrosion of Polycrystalline Titanium by Using Different Techniques." Journal of the Electrochemical Society, 145, 2005-2010 (1998).

[124] Kamikubo, F., Satoh, H., Shimogori, K., and Fukuzuka, T., "Effects of a Small Amount of Impurity Elements on Pitting Potential of Commercially Pure Titanium in Sodium Bromide Solutions." In Proceedings of the Eighth International Congress on Metallic Corrosion, DECHEMA, Frankfurt/Main, Germany, 1378-83 (1981). 
[125] Curty, C. and Virtanen, S., "Initiation Events of Pitting Corrosion of Titanium." Electrochemical Society Proceedings, 99-27. 445-452 (1999).

[126] Fontana, M.G., "Corrosion Engineering." 3rd Edition (1986).

[127] Revie, R.W., Uhlig's Corrosion Handbook. 2nd Edition. John Wiley \& Sons, Inc. (2000).

[128] Little, B. and Wagner, P., "An Overview of Microbiologically Influenced Corrosion of Metals and Alloys Used in the Storage of Nuclear Wastes." Canadian Journal of Microbiology, 42, (4), 367-374 (1996).

[129] Else, T.A., Pantle, C.R, Amy, P.S., "Boundaries for Biofilm Formation: Humidity and Temperature." Applied. Environ. Microbiol. 69, 5006-5010 (2003).

[130] BSC, "General Corrosion and Localized Corrosion of Waste Package Outer Barrier." ANL-EBS-MD-000003 REV 01. Las Vegas, Nevada: Bechtel SAIC Company (2003).

[131] Cheng, T-P., Lee, J-T., and Tsai, W-T., "Galvanic Corrosion of Titanium-Coupled Aluminum Bronze." Materials Chemistry and Physics, 36, 156-160 (1993).

[132] Shifler, D.A., Melton, D., and Hack, H.P., "New Techniques for Galvanic Corrosion Prevention in Piping Systems." Proceedings of the 1997 Tri-Service Conference on Corrosion, Wrightsville Beach, North Carolina, November 17-21, 1997, Naval Surface Warfare Center-Carderock Division. 1, 1-22 (1997).

[133] Schutz, R.W., "Titanium." Process Industries Corrosion. 503-527 (1986).

[134] Reclaru, L. and Meyer, J.-M., "Effects of Fluorides on Titanium and Other Dental Alloys in Dentistry." Biomaterials, 19, 85-92 (1998).

[135] Sundgren, J.E., Bodo, P., and Lundstrom, I., "Auger Electron Spectroscopy Studies of the Interface Between Human Tissue and Implants of Titanium and Stainless Steel." J. Colloid and Interfacial Science, 110, 9-20 (1986).

[136] Hanawa, T., Asami, K., and Asaoka, K., "Repassivation of Titanium and Surface Oxide Film Regenerated in Simulated Bioliquid." J. Biomed. Mat. Res, 40, 530-538 (1998).

[137] Hanawa, T. and Ota, M., "Characterization of Surface Films Formed on Titanium in Electrolyte Using XPS." Surface Science, 55, 269-276 (1992).

[138] Molecke, M.A., Ruppen, J.A., and Diegle, R.B., "Materials for High-Level Waste Canister/Overpacks in Salt Formations." Sandia National Laboratory Report, SAND82-0429 (1982).

[139] Smailos, E., Schwarzkopf, W., Köster, R., Fiehn, B., and Halm, G., "Corrosion Testing of Selected Packaging Materials for Disposal of High Level Waste Glass in Rock-Salt Formations." Commission of the European Communities Report, EUR-13672-EN (1991).

[140] Shoesmith, Private comminucation (2003).

[141] Schutz, R.W. and J.S. Grauman. "Localized Corrosion of Titanium Alloys in High Temperature Seawater Service.” Corrosion 88, Paper No. 162 (1988). 


\title{
A REVIEW CORROSION OF TI GRADE 7 AND OTHER TI ALLOYS IN NUCLEAR WASTE REPOSITORY ENVIRONMENTS
}

\author{
US DOE Yucca Mountain Project M\&O \\ ${ }^{*}$ Bechtel SAIC Company, LLC \\ ${ }^{\dagger}$ Framatome ANP \\ 1180 Town Center Dr. \\ Las Vegas, NV 89144, USA \\ David Shoesmith \\ Department of Chemistry \\ University of Western Ontario \\ London, ON, N6A 5B7, Canada
}

Fred Hua*, Kevin Mon ${ }^{\dagger}$, Pasu Pasupathi* and Gerald Gordon ${ }^{\dagger}$

\begin{abstract}
Titanium alloy degradation modes are reviewed in relation to their performance in repository environments. General corrosion, localized corrosion, stress corrosion cracking, hydrogen induced cracking, microbially influenced corrosion, and radiation-assisted corrosion of $\mathrm{Ti}$ alloys are considered. With respect to the $\mathrm{Ti}$ Grade 7 drip shields selected for emplacement in the repository at Yucca Mountain, general corrosion, hydrogen induced cracking, and radiation-assisted corrosion will not lead to failure within the 10,000 year regulatory period; stress corrosion cracking (in the absence of disruptive events) is of no consequence to barrier performance; and localized corrosion and microbially influenced corrosion
\end{abstract}


are not expected to occur. To facilitate the discussion, Ti Grades 2, 5, 7, 9, 11 , $12,16,17,18$, and 24 are included in this review.

Keywords: Titanium alloys, Repository environments, Palladium, Passive film, Hydrogen induced cracking, General corrosion, Localized corrosion, Stress corrosion cracking.

\section{INTRODUCTION}

The Nuclear Waste Policy Act of 1982 as amended in 1987 designated Yucca Mountain as the site to be characterized for high-level nuclear waste (HLW) disposal [1]. Long-term containment of the waste and subsequent slow release of radionuclides from the Engineered Barrier System (EBS) into the geosphere will rely on a system of natural and engineered barriers including a robust waste containment design. During the Site Recommendation (SR) phase of the Project, a container design using a highly corrosion resistant Ni-based Alloy 22 cylindrical barrier surrounding a 316 stainless steel inner structural container was adopted [2]. The waste package is covered by a self-supported mailbox-shaped drip shield (DS) composed predominantly of Ti Grade 7 with Ti Grade 24 structural support members [2]. The Ti drip shield protects the waste package against rock fall and limits the contact of the waste form to dripping water. The minimum target for isolation of HLW without exceeding a regulatory specified individual dose rate at the site boundary is 10,000 years [3]. Numerous studies have been performed to 
evaluate the susceptibility to stress corrosion cracking, general, localized, galvanic and microbially influenced corrosion for Alloy $22[4,5,6,7,8,9,10$, 11] and Ti Grade $7[5,6,12,13,14]$.

The purpose of this work is to review the corrosion performance of Ti Grade 7 and other relevant titanium alloys under repository conditions. A brief review of the background of titanium alloys, hydrogen absorption and the properties of passive film on titanium alloys will be given as the basis of the discussion. Next, the key corrosion processes that could occur will be addressed individually. Finally, the expected corrosion performance of these alloys under the specific environmental conditions anticipated at Yucca Mountain will be considered.

\section{METALLURGICAL ASPECTS OF TITANIUM ALLOYS}

Pure titanium is an allotropic element, existing in more than one crystallographic form [15]. Above $883^{\circ} \mathrm{C}$ it has the body-centered cubic (bcc) crystal structure, known as the beta $(\beta)$ phase. Below $883^{\circ} \mathrm{C}$, it transforms to the hexagonal closepacked (hcp) alpha $(\alpha)$ phase. The chemical compositions and mechanical properties, per ASTM B 265-02 [16], of the several titanium alloys are shown in Table 1 and Table 2. Ti Grades 2, 7, 12, and 16 are $\alpha$-alloys while Ti Grades 5 and 24 are $\alpha-\beta$ alloys. Ti Grade 7 contains a slightly higher wt $\%$ of palladium $(0.12-0.25 \mathrm{wt} \%)$ than Ti Grade $16(0.04-0.08 \mathrm{wt} \%)$. The ASTM B 265-02 specified mechanical properties are identical for Ti Grades 2, 7, and 16; and $\mathrm{Ti}$ 
Grades 5 and 24; and Ti Grades 9 and 18. The relationships of interest between titanium alloys are schematically shown in Figure 1.

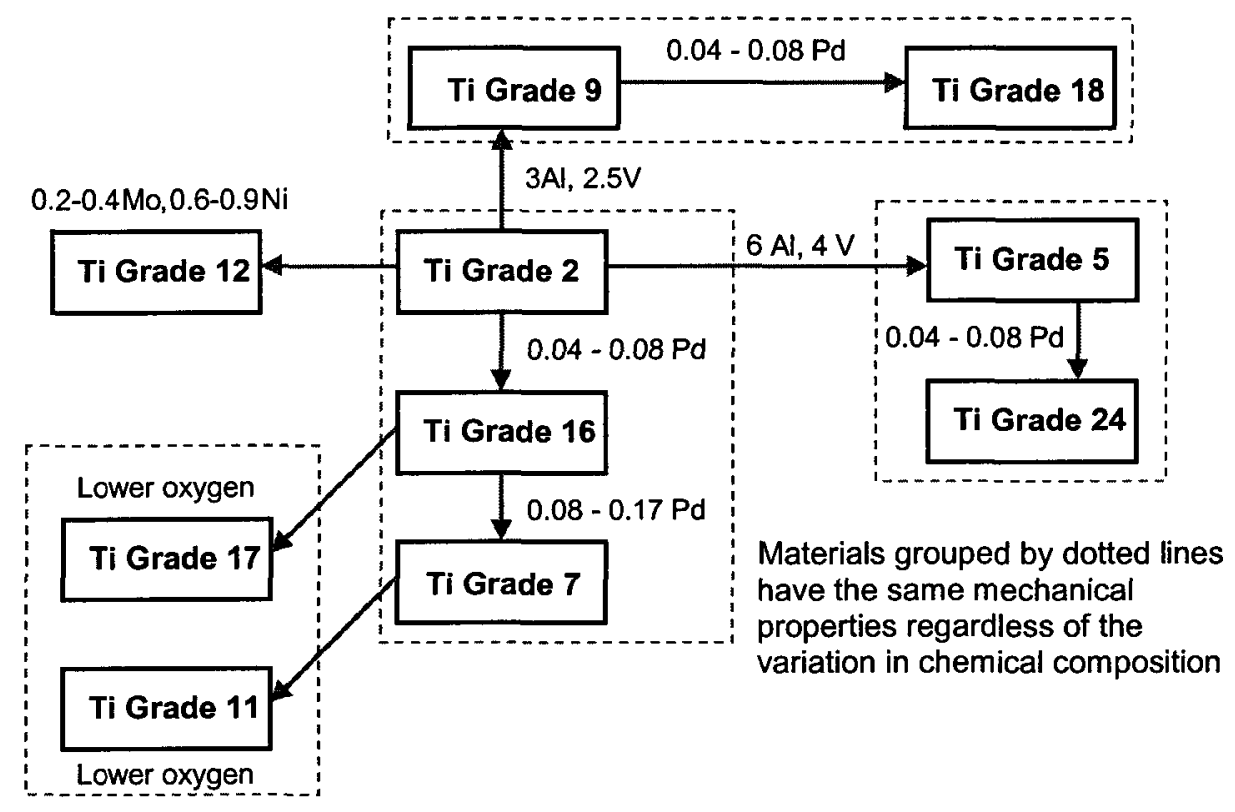

FIGURE 1. Schematic of the relationship between the relevant titanium alloys. Alloys grouped by the dotted lines have the same mechanical properties regardless of chemical composition.

Table 1. ASTM Specifications for chemical composition requirements (wt \%) for relevant titanium alloys in this review (ASTM 2002)

\begin{tabular}{|l|c|c|c|c|c|c|c|c|c|c|c|}
\hline Material & UNS & $\mathrm{N}$ & $\mathrm{C}$ & $\mathrm{H}$ & $\mathrm{O}$ & $\mathrm{Fe}$ & $\mathrm{Al}$ & $\mathrm{V}$ & $\mathrm{Pd}$ & $\begin{array}{c}\text { Residual } \\
\text { (each) }\end{array}$ & $\begin{array}{c}\text { Residual } \\
\text { (total) }\end{array}$ \\
\hline Grade 12 & R53400 & 0.03 & 0.08 & 0.015 & 0.25 & 0.30 & - & - & - & $0.2-0.4$ & $0.6-0.9$ \\
$\mathrm{Mo}$ & $\mathrm{Ni}$ \\
\hline Grade 2 & $\mathrm{R} 50400$ & 0.03 & 0.08 & 0.015 & 0.25 & 0.30 & - & - & - & 0.1 & 0.4 \\
\hline Grade 7 & $\mathrm{R} 52400$ & 0.03 & 0.10 & 0.015 & 0.25 & 0.30 & - & - & $0.12-0.25$ & 0.1 & 0.4 \\
\hline Grade 16 & $\mathrm{R} 52402$ & 0.03 & 0.08 & 0.015 & 0.25 & 0.30 & - & - & $0.04-0.08$ & 0.1 & 0.4 \\
\hline Grade 17 & $\mathrm{R} 52252$ & 0.03 & 0.08 & 0.015 & 0.18 & 0.20 & - & - & $0.04-0.08$ & 0.1 & 0.4 \\
\hline Grade 11 & R52250 & 0.03 & 0.10 & 0.015 & 0.18 & 0.20 & - & - & $0.12-0.25$ & 0.1 & 0.4 \\
\hline Grade 5 & R56406 & 0.05 & 0.08 & 0.015 & 0.20 & 0.40 & $5.5-6.75$ & $3.5-4.5$ & - & 0.1 & 0.4 \\
\hline Grade 24 & R56405 & 0.05 & 0.08 & 0.015 & 0.20 & 0.40 & $5.5-6.75$ & $3.5-4.5$ & $0.04-0.08$ & 0.1 & 0.4 \\
\hline Grade 9 & R56320* & 0.03 & 0.08 & 0.015 & 0.12 & 0.25 & $2.5-3.5$ & $2.0-3.0$ & - & 0.1 & 0.4 \\
\hline Grade 18 & R56322 & 0.03 & 0.08 & 0.015 & 0.15 & 0.25 & $2.5-3.5$ & $2.0-3.0$ & $0.04-0.08$ & 0.1 & 0.4 \\
\hline
\end{tabular}

* UNS R56320 requires lower $N, C, O$ and $H$. 
Table 2. ASTM Specifications for mechanical properties of relevant titanium alloys in this review (ASTM 2002)

\begin{tabular}{|c|c|c|c|c|c|c|c|c|}
\hline \multirow{3}{*}{ Material } & \multirow{3}{*}{$\begin{array}{c}\text { UNS } \\
\text { Designation }\end{array}$} & \multicolumn{2}{|c|}{$\begin{array}{c}\text { Minimum Tensile } \\
\text { Strength }\end{array}$} & \multicolumn{4}{|c|}{ Yield Strength, $0.2 \%$ Offset } & \multirow{3}{*}{$\begin{array}{l}\text { Minimum } \\
\text { Elongation } \\
\text { in } 2 \text { in., } \%\end{array}$} \\
\hline & & \multirow{2}{*}{ ksi } & \multirow{2}{*}{$\mathrm{MPa}$} & & & & & \\
\hline & & & & ksi & $\mathrm{MPa}$ & ksi & $\mathrm{MPa}$ & \\
\hline Grade 12 & R53400 & 70 & 483 & 50 & 345 & - & - & 19 \\
\hline Grade 2 & $\mathrm{R} 50400$ & 50 & 345 & 40 & 275 & 65 & 450 & 20 \\
\hline Grade 7 & R52400 & 50 & 345 & 40 & 275 & 65 & 450 & 20 \\
\hline Grade 16 & $\mathrm{R} 52402$ & 50 & 345 & 40 & 275 & 65 & 450 & 20 \\
\hline Grade 17 & R52252 & 35 & 240 & 25 & 170 & 45 & 310 & 24 \\
\hline Grade 11 & R52250 & 35 & 240 & 25 & 170 & 45 & 310 & 24 \\
\hline Grade 5 & R56406 & 130 & 895 & 120 & 828 & - & - & 10 \\
\hline Grade 24 & R56405 & 130 & 895 & 120 & 828 & - & - & 10 \\
\hline Grade 9 & R56320* & 90 & 620 & 70 & 483 & - & - & 15 \\
\hline Grade 18 & R56322 & 90 & 620 & 70 & 483 & - & - & 15 \\
\hline
\end{tabular}

The solubility of hydrogen in $\alpha$-titanium at room temperature is very low (on the order of 20 to $150 \mathrm{ppm}$ ) [17]. Once the hydrogen solubility is exceeded, brittle titanium hydride precipitates can form leading to hydrogen embrittlement: At high stress intensities, hydrogen-assisted localized plasticity at the crack tip (i.e., hydrogen enhanced dislocation flow) can occur [18]. The effects of hydrogen on mechanical properties will be referred to generically as hydrogen induced cracking (HIC). Hydrogen solubility in the $\beta$-phase is greater than in the $\alpha$-phase $(>9000 \mathrm{ppm})[17]$ resulting in strong effects of microstructure on HIC in near- $\alpha$ (containing small amounts of $\beta$ ) and $\alpha-\beta$ alloys. Alloys with continuous $\beta$-phases provide fast diffusion paths for hydrogen and are more susceptible to HIC than alloys with continuous $\alpha$-phase [19].

\section{EFFECTS OF ALLOYING ELEMENTS}

One purpose of adding alloying elements to titanium is to enhance corrosion resistance in reducing acids. This is particularly true for alloying with platinum 
group metals (PGMs) [20, 21]. PGMs are characterized by very low hydrogen overpotential and accelerated hydrogen ion reduction kinetics in acid solutions [22]. This results in a reduced cathodic Tafel slope and depolarization of the cathodic hydrogen reduction process.

\section{Enrichment of Alloying Elements on Titanium Surface}

For Ti Grade 12 (alloyed with Ni and Mo), Ti Grades 7 and 16 (alloyed with Pd), and Ti-Ru alloys, it has been proposed that corrosion in acidic environments leads to the release and redeposition of alloying elements to produce sites that act as proton reduction catalysts $[23,24,25,26,27,28,29]$. Depolarization of proton reduction at these sites shifts the alloy potential to more positive values thereby promoting passivity. For Ti Grade 12, another explanation has been proposed, $\mathrm{Ti}_{2} \mathrm{Ni}$ intermetallics act as catalytic cathodes galvanically-coupled to the surrounding Ti $\alpha$-grains $[30,31]$. This is supported by evidence of $\mathrm{Ni}^{2+}$ in solution during passive corrosion. For Pd-containing alloys, either metal dissolution or oxide growth could lead to Pd enrichment on the surface, and to ennoblement (Figure 3) [32]. Evidence for accumulation of Pd on the surface during corrosion in acid solutions is indisputable [33]. Whether this is due to the redeposition of dissolved $\mathrm{Pd}^{2+}$ or the accumulation of $\mathrm{Pd}$ after preferential dissolution of $\mathrm{Ti}[33,34]$ is unclear. 


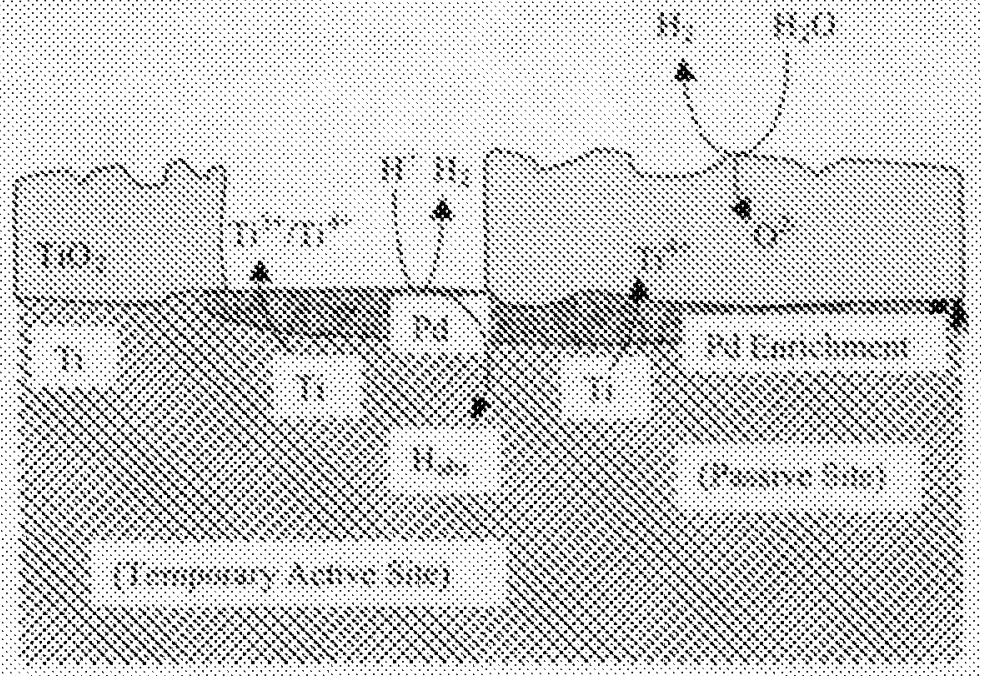

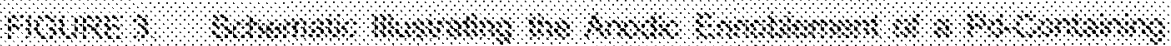

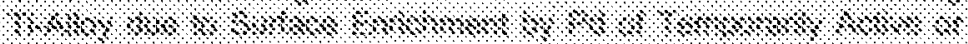
\$ 1,1,

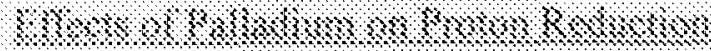

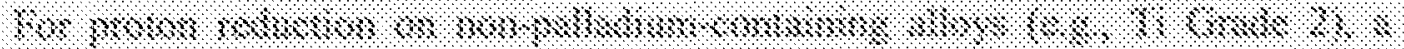

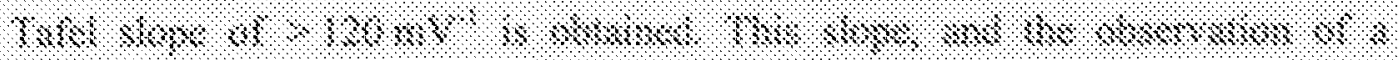

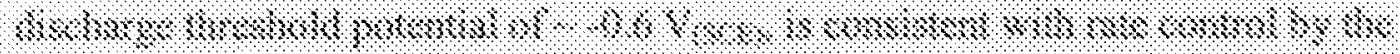

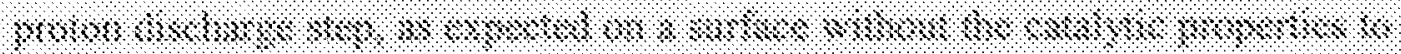

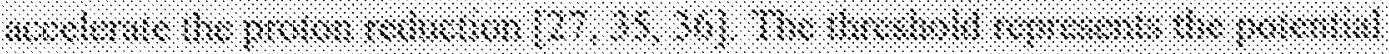

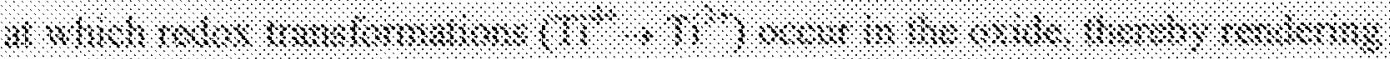

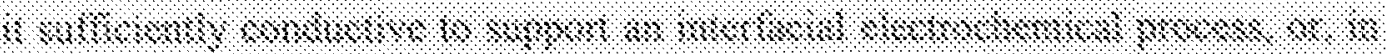

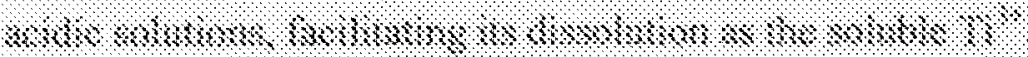

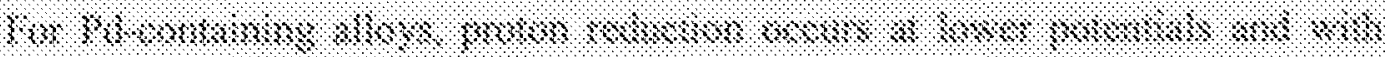

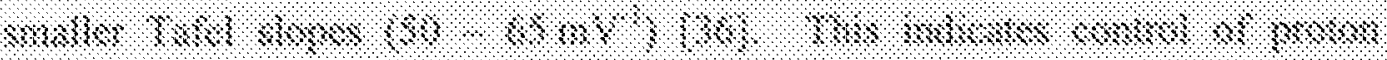

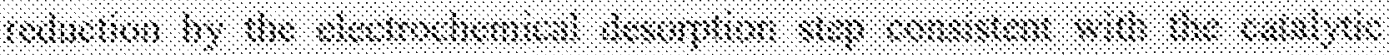


behavior observed on noble metals such as Pd [36]. Schutz and Xiao [27] made similar observations on Ti Grade 2 compared to Ti Grades 7 and 16. The Tafel slope for Ti Grade $16\left(100 \mathrm{mV}^{-1}\right)$ was larger than that obtained for Ti Grade 7 $\left(80 \mathrm{mV}^{-1}\right)$ indicating that the ability to catalyze proton reduction decreases as the Pd content of the alloy decreases. These results are consistent with those of Fukuzuka et al. [42], who showed enhanced proton reduction was possible at lower potentials on Pd-containing alloys than on Ti Grade 2. This indicates that redox transformations in the oxide are not a prerequisite for proton reduction. A possible explanation is proton reduction can occur on intermetallic precipitates rich in noble metal content which can function as "hydrogen windows" in the oxide [32]. This process depends on the catalytic properties of the cathodic sites, however, the alloying elements added, $\mathrm{Ni}, \mathrm{Pd}, \mathrm{Ru}$, are known to facilitate proton reduction [36] and have significant solubilities for hydrogen.

\section{Effects of Palladium and Other Alloying Additions on Hydrogen Absorption}

If a coherent layer of $\mathrm{TiO}_{2}$ exist over intermetallic precipitates, the precipitates may act as "hydrogen windows" in the oxide [32]. Under these circumstances, transformation of the redox properties of the passive oxide (on cathodic polarization) may not be a necessary prerequisite for hydrogen absorption, which could, therefore, occur at potentials more positive than $-0.6 \mathrm{~V}$. For the Pdcontaining alloys, the amount of $\beta$-phase is negligible and intermetallic particles, 
when present, appear inert to corrosion $[37,38]$. Under acidic conditions, the rate and efficiency of hydrogen absorption increases with increasing Pd content, though, in the absence of any apparent separation of the Pd into discrete intermetallics, the mechanism of absorption remains unclear. Presumably, the discharge step and the subsequent $\mathrm{H}$ absorption step occur at the atomic level. Since absorption can occur for $\mathrm{E}>-0.6 \mathrm{~V}$, redox transformations within the oxide do not appear to be a prerequisite.

For Ti Grade 16, Ikeda and Quinn $[39,40]$ found that $\mathrm{H}$ absorption is not observed for applied potentials as low as $-1.0 \mathrm{~V}$, despite the presence of a large number of randomly dispersed intermetallic particles. Although the material investigated contained a substantial amount of $\mathrm{Fe}$ (as an impurity), intermetallic particles were apparently inert to corrosion in acidic solutions (which $\mathrm{Ti}_{x} \mathrm{Fe}$ particles are not), indicating that $\mathrm{Pd}$ cosegregated to yield TiPdFe particles. Hydrogen absorption may not have been observed because the experiments were conducted in neutral solutions where a passive oxide, impermeable to hydrogen (see below), may have been present on the particles.

Experimental evidence for the enhancement of hydrogen absorption due to Pd addition is not conclusive. Alloying Pd with titanium might promote hydrogen absorption [41], however other investigators showed that Ti-Pd alloys are not sensitive to hydrogen absorption [42, 43]. Fukuzuka et al. [42] demonstrated that, 
while the hydrogen absorption efficiency of Ti-Pd alloys increased with Pd content in deaerated $\mathrm{HCl}$, both the corrosion rate and hydrogen absorption efficiency decreased when the $\mathrm{HCl}$ was aerated. This influence of aeration was attributed to the ennoblement of the corrosion potential due to the addition of Pd, and to the low over-voltage of Pd for oxygen reduction.

The intermetallic compound $\mathrm{Ti}_{2} \mathrm{Ni}$ has been shown to be the active cathode in $\mathrm{Ti}$ Grade 12 (Figure 5a) [30]. Since the solubility of hydrogen in $\mathrm{Ti}_{2} \mathrm{Ni}$, and to a lesser degree the $\beta$-phase, is substantially higher than in the $\alpha$-phase, their presence in Ti Grade-12 would enhance hydrogen absorption. An additional feature of Ti Grade-12 is the location of the $\beta$-phase as ligaments along the $\alpha$-Ti grain boundaries [30]. This geometry, coupled with the higher diffusion rate of $\mathrm{H}$ in $\beta$-phase [44] would facilitate the transport of hydrogen into the alloy.

Both Ni- and Pt-coated titanium electrodes readily absorb hydrogen for $\mathrm{pH}<3$ with efficiencies up to $60 \%$ in acidic solutions at $25^{\circ} \mathrm{C}$, Figure $5 \mathrm{~b}$ [45]. At $40^{\circ} \mathrm{C}$, the absorption efficiency rose to over $80 \%$. While these results indicate that $\mathrm{Ni}$ or Pd (expected to behave like Pt) deposits in active crevices have a major effect on hydrogen absorption, they do not represent the expected behavior under noncreviced conditions. Figure $5 \mathrm{~b}$ shows a strong influence of $\mathrm{pH}$ on the absorption efficiency, suggesting that a stable passive film severely retards hydrogen 


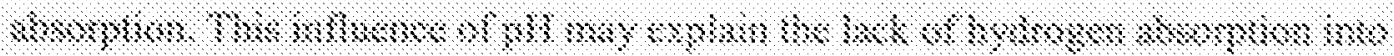
(4)

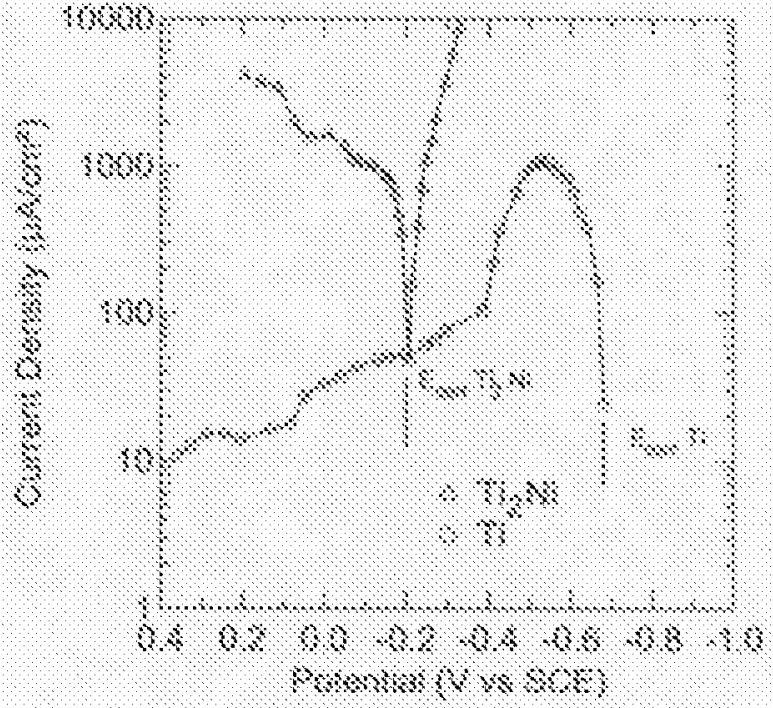

6

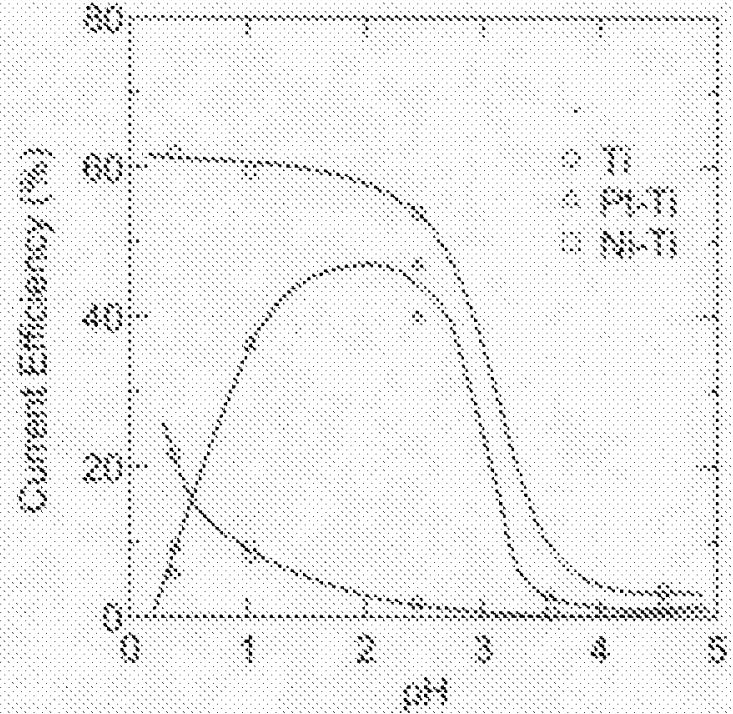

8 )

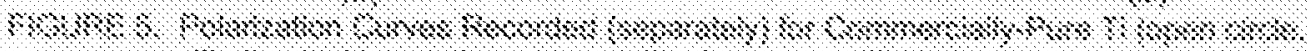

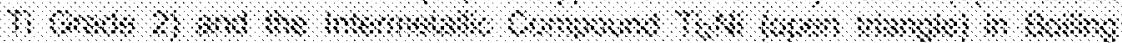

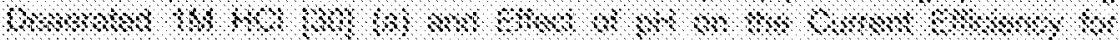

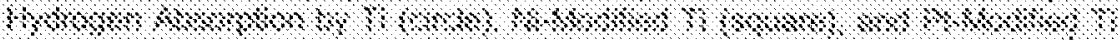

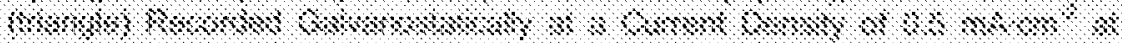

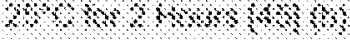

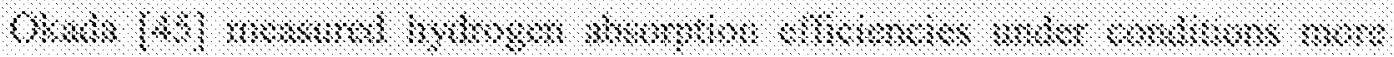

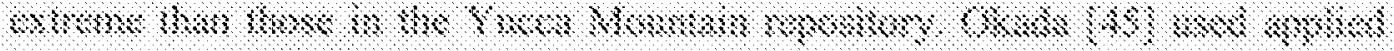

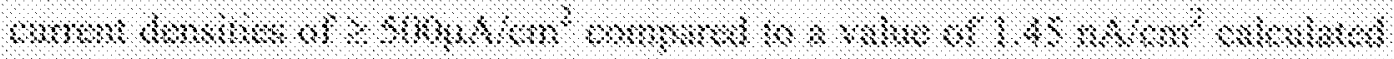

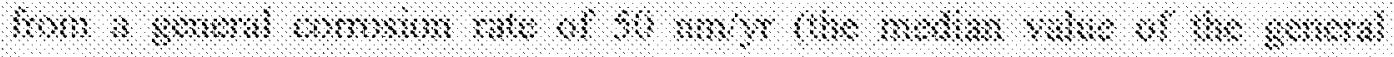

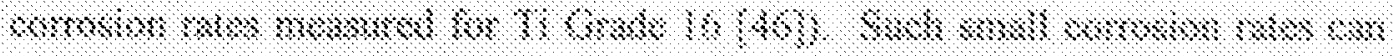

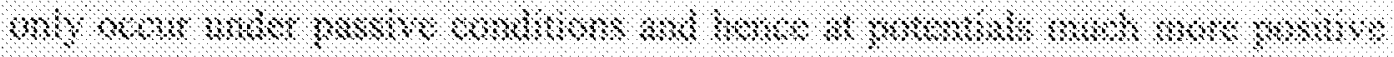


than those enforced galvanostatically in Okada's experiments. Thus, it is extremely unlikely that, in the absence of acidified crevices, significant hydrogen absorption will occur under repository conditions.

The most common impurity in titanium alloys is Fe. Watanabe et al. [47] showed that when the concentration of Fe was in excess of the $\sim 0.03 \mathrm{wt} . \%$ solubility limit, precipitation of $\mathrm{Ti}_{\mathrm{x}} \mathrm{Fe}$ particles occurred. $\mathrm{Ti}_{\mathrm{x}} \mathrm{Fe}$ would be expected to behave in a manner similar to that observed for $\mathrm{Ti}_{2} \mathrm{Ni}$ in $\mathrm{Ti}$ Grade 12. Studies of the influence of Fe on corrosion and hydrogen absorption of Ti have yielded conflicting results $[48,49,50]$, likely due to variations in the distribution of Fe within the metal matrix. While the intermetallic $\mathrm{Ti}_{\mathrm{x}} \mathrm{Fe}$ has been shown to be a hydrogen absorber, it is difficult to activate for hydrogen storage [51] and could actually impede hydrogen absorption despite acting as a $\mathrm{H}^{+}$reduction catalyst. According to $\mathrm{Wu}$ [51], the hydride formed on this intermetallic possesses less lattice distortion than that formed on $\alpha-\mathrm{Ti}$, which would retard the diffusion of hydrogen. Similar speculations have been offered by Schutz et al. [50]. Such mechanistic features could lead to decreased $\mathrm{H}$ absorption with increasing Fe content.

From these results it is clear that the $\mathrm{Ni}$ and Fe distribution can have a significant influence on the corrosion behavior of Ti Grade 12 (containing both $\mathrm{Ni}$ and $\mathrm{Fe}$ ) and Ti Grade 2 (contaminated with $\mathrm{Fe}$ ) and their ability to absorb hydrogen. It is 


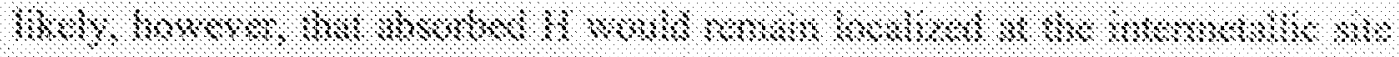

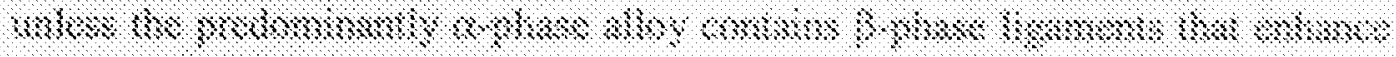

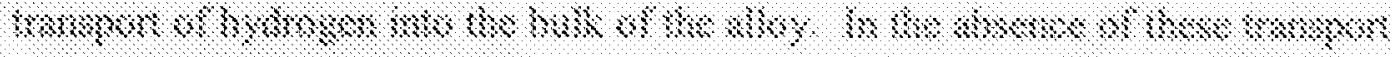

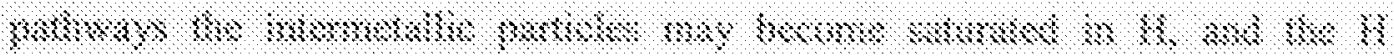

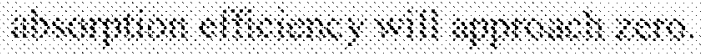

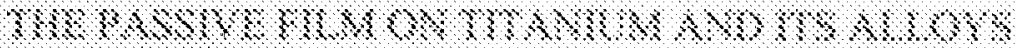

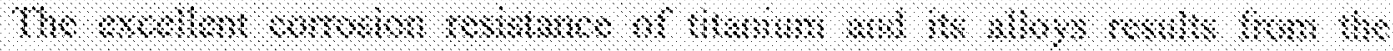

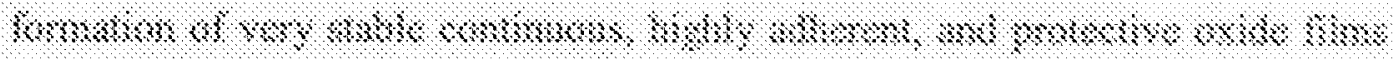

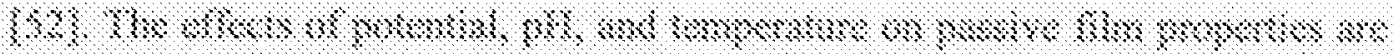

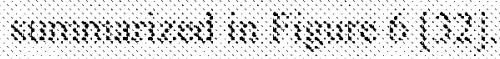

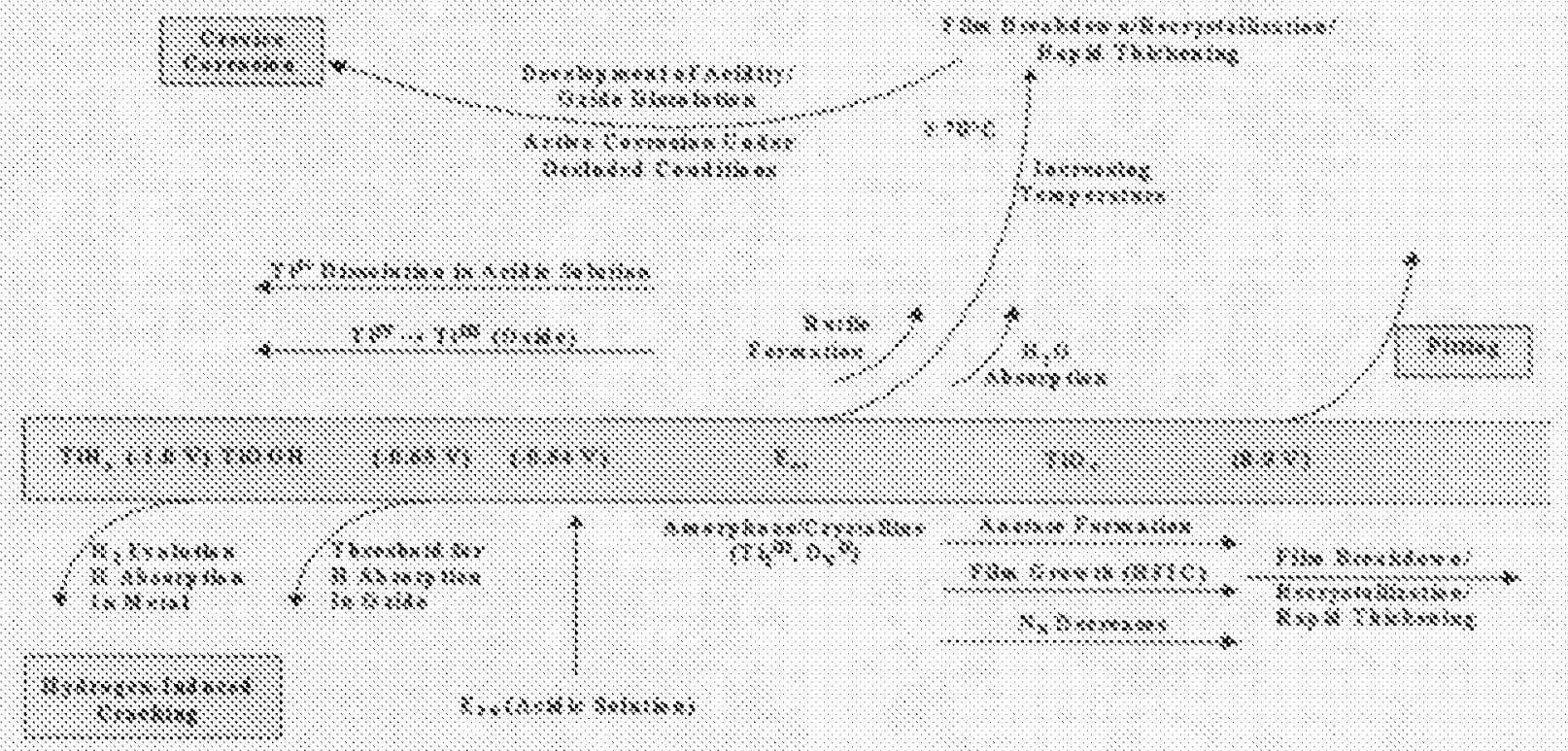

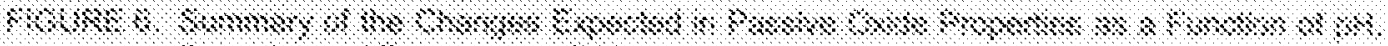
$\$, \$, \$, \$ 3$

$18 \times 8 \% 8 \% 8 \% \%$ 
The passive oxide grown under open-circuit conditions at room temperature may be amorphous or crystalline, depending on the conditions of growth. The thickness of the oxide and its degree of crystallinity may vary spatially [53], and a small degree of non-stoichiometry (in the form of oxygen vacancies and $\mathrm{Ti}^{3+}$ interstitial ions) gives the oxide n-type semiconducting properties.

Anodic polarization leads to oxide thickening and a decrease in the number density of defects. Amorphous films recrystallize to anatase over the potential range 4 to $\sim 7 \mathrm{~V}_{\text {(SCE) }}$ and cracks and faults begin to appear in the oxide [54]. The amount of water absorbed by the oxide, which generally leads to an improvement in passivity, does not increase with increasing applied potential. Below $1.0 \mathrm{~V}_{(\mathrm{SCE})}$, hydrogen evolution occurs and the formation of surface hydrides is observed. Measurements of the amount of hydrogen absorbed suggest a threshold potential of $\sim-0.6 \mathrm{~V}$ above which no hydrogen absorption occurs.

\section{Effect of Temperature}

The effect of temperature on passive films is similar to that of potential. A similar breakdown/recrystallization process to yield anatase/rutile occurs in the temperature range $50^{\circ} \mathrm{C}$ to $70^{\circ} \mathrm{C}$, but in contrast to the effect of potential, is accompanied by the absorption of water. Above $\sim 70^{\circ} \mathrm{C}$, the rate of film thickening increases as observed at high potentials, but the amount of absorbed water also increases markedly. Subsequent examination at room temperature in 
$\mathrm{NaBr}$ solutions shows this absorption of water improves the passivity of the oxide as indicated by a marked increase in pitting potential [55].

\section{Effect of $\mathrm{pH}$}

$\mathrm{pH}$ has no effect on oxide stability at potentials above $-0.3 \mathrm{~V}_{(\mathrm{SCE})}$. Under sufficiently acidic conditions an active region and an active to passive transition are observed between $\sim-0.7$ and $-0.3 \mathrm{~V}_{(\mathrm{SCE})}[56]$. In chloride solutions at room temperature, a $\mathrm{pH}$ between 1 and 0 is required before active conditions can be established [57]. For a temperature of $70^{\circ} \mathrm{C}$, a $\mathrm{pH}<1$ is required. For natural corrosion conditions, the dissolution of the oxide film in acidic solutions is slow $\left(\sim 20 \mu \mathrm{m} / \mathrm{yr}\right.$ at $\mathrm{pH}<0$ and $\left.45^{\circ} \mathrm{C}\right)$, and in solutions of $\mathrm{pH}>1$, extremely slow $\left(\sim 2 \mu \mathrm{m} / \mathrm{yr}\right.$ at $\mathrm{pH} \sim 1$ and $\left.45^{\circ} \mathrm{C}\right)$ [58]. Cathodic polarization in acidic solutions leads

to the reductive dissolution of the oxide [59], a process which is accompanied by the absorption of hydrogen into the oxide.

\section{The Role of Passive Film in Retarding Hydrogen Absorption}

For $\mathrm{H}$ absorption to occur it is necessary to have cathodic polarization, redox transformations within the oxide or "hydrogen windows" at intermetallic sites. The need for hydrogen to penetrate the oxide accounts for the existence of a threshold potential $(<-0.7 \mathrm{~V}[52])$ as demonstrated in long term hydrogen absorption measurements by Murai et al. (Figure 7) [35]. Once the potential is sufficiently negative for redox transformations to occur, titanium hydrides are thermodynamically stable with respect to the metal $[60,61]$. Below this threshold 
potential, the rate of absorption of hydrogen by the metal is effectively independent of potential down to $\sim-1.0 \mathrm{~V}_{(\mathrm{SCE})}$ as shown in Figure 7. No significant hydrogen transport through the oxide film occurs until potentials is below $-1.0 \mathrm{~V}_{(\mathrm{SCE})}[52,62]$.

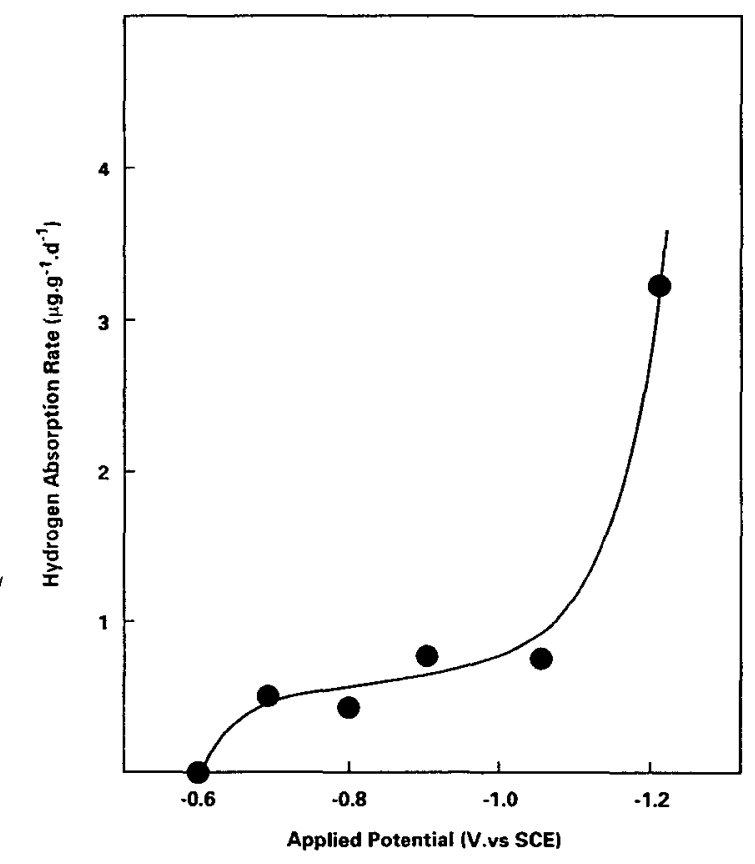

FIGURE 7. The Hydrogen Absorption Rate as a Function of Applied Potential Measured on $\mathrm{Ti}$ Grade 2 Electrodes in Flowing Artificial Seawater with a Flow Velocity of $2.0 \mathrm{~ms}^{-1}$ at $30^{\circ} \mathrm{C}[35]$.

A stable passive oxide opposes any tendency for Pd to accelerate hydrogen absorption [45]. The rate of hydrogen absorption decreases parabolically with exposure time even under cathodic polarization when hydrogen absorption would be expected to be accelerated $[63,64,65]$. The parabolic dependence suggests 
that surface absorption sites are becoming saturated and the rate of absorption becomes controlled by the rate of diffusive transport, a very slow process for $\alpha$ alloys (Ti Grades 2, 7, and 16). This is true even for Ti Grade 12 which is expected to be more prone to hydrogen absorption because of the presence of $\mathrm{Ni}$ stabilized $\beta$-phase and $\mathrm{Ti}_{2} \mathrm{Ni}$ precipitates, both of which support proton reduction and have a high solubility for hydrogen $[64,65]$. Other investigations have shown that thermally grown oxides suppress hydrogen absorption in aggressive brine environments $(6 \% \mathrm{NaCl})$ up to about $120^{\circ} \mathrm{C}$ [66] and hydrogen absorption observed in deaerated $\mathrm{HCl}\left(2 \leq \mathrm{pH} \leq 4 ; 50^{\circ} \mathrm{C}\right.$ to $\left.250^{\circ} \mathrm{C}\right)$ was completely stopped by aerated conditions [67].

The Role of The Passive Film In Resisting Fluoride-Enhanced Corrosion

The aggressiveness of fluoride in acidic solutions is well characterized [68]. Wilhelmsen and Grande [69] confirmed direct incorporation of $\mathrm{F}^{-}$into the passive film only occurred under acidic conditions. A combination of a significant $\mathrm{F}^{-}$ concentration $(>500 \mu \mathrm{g} / \mathrm{g}$ ) and a low $\mathrm{pH}$ is critical for the loss of passivity [70, 71]. Brossia et al. [72], who used freshly polished specimens observed significant passive current density increases on Ti Grade 7 in $1 \mathrm{M} \mathrm{NaCl}\left(95^{\circ} \mathrm{C}\right)$ for fluoride concentrations $\geq 10 \mathrm{mg} / \mathrm{L}$. In contrast, Lorenzo de Melo and Cortizo [73] showed that fluoride additions (to a $\mathrm{pH}=6.5$ solution) had no effect on passivity if an oxide film had been pregrown. They concluded that the susceptibility of titanium to corrosion in $\mathrm{F}^{-}$was associated with defects and flaws in the oxide [73]. 
Consistent with these observations, excellent corrosion behavior has been observed on both uncreviced and creviced Ti Grade 16 and Ti Grade 7 specimens with pregrown films (in ambient air) tested in the LTCTF [74]. Corrosion rates observed in LTCTF test solutions, including SCW which contained $\sim 1000 \mathrm{X} \mathrm{J}-13$ ionic concentration with $\sim 1,619 \mathrm{mg} / \mathrm{L} \mathrm{F}^{-}, 5,047 \mathrm{mg} / \mathrm{L} \mathrm{Cl}^{\circ}$, and a $\mathrm{pH}$ of $\sim 8-10$, were not high enough to cause failure by general corrosion within the 10,000 year regulatory time period.

The above discussion suggests that, similar to $\mathrm{Cl}^{-}, \mathrm{F}^{-}$utilizes defects within the oxide in order to initiate oxide breakdown rather than chemically-attacking the outer oxide surface. Pan et al. [75] and Blackwood et al. [58] concluded that films with lower defect density had lower dissolution rates. Choi et al. [76] have shown that thermal treatments not only thicken the oxide film but also decrease the defect density in the film by a factor between $10^{2}$ and $10^{4}$ compared to films grown in aqueous environments. Since, according to Hurlen and Hjornkol [77], the kinetics of passive corrosion of titanium in neutral solutions are controlled by the migration of defects across the oxide film, an increase in thickness and decrease in defect density would lead to a significant decrease in susceptibility to fluoride induced film breakdown.

\section{GENERAL CORROSION}

\section{Vapor-Phase Corrosion}


The oxide film on Ti provides an excellent barrier to corrosive attack by most gases in wet and dry conditions, including $\mathrm{O}_{2}, \mathrm{~N}_{2}$, dry $\mathrm{HCl}, \mathrm{SO}_{2}, \mathrm{NH}_{3}, \mathrm{HCN}, \mathrm{CO}_{2}$, $\mathrm{CO}$ and $\mathrm{H}_{2} \mathrm{~S}$ [52]. Dry air conditions are most relevant to the repository since when the temperature is high the relative humidity will be low. For Ti alloys, logarithmic growth kinetics are expected for temperatures $<400^{\circ} \mathrm{C}[78]$. The corrosion performance of Ti Grades 2 and 7 has been investigated in clay and moist clay atmospheres at 90 and $170^{\circ} \mathrm{C}$ for exposure periods up to 6 years [79, $80,81]$. No measurable differences in performance were observed between these alloys even in the presence of a radiation field $\left(10^{3} \mathrm{~Gy} / \mathrm{h} \equiv 10^{5} \mathrm{R} / \mathrm{h}\right)[82]$.

TABLE 3. TARGET CHEMICAL COMPOSITIONS OF THE ELECTROLYTE SOLUTIONS USED IN THE YUCCA MOUNTAIN PROJECT'S TESTING PROGRAMS

\begin{tabular}{|c|c|c|c|c|c|}
\hline Ion & $\begin{array}{c}\text { SDW } \\
\left(\mathrm{mg} / \mathrm{L}^{-1}\right)\end{array}$ & $\begin{array}{c}\mathbf{S C W} \\
\left(\mathrm{mg} / \mathrm{L}^{-1}\right)\end{array}$ & $\begin{array}{c}\text { SAW } \\
\left(\mathrm{mg} / \mathrm{L}^{-1}\right)\end{array}$ & $\begin{array}{c}\mathbf{S S W} \\
\left(\mathrm{mg} / \mathrm{L}^{-1}\right)\end{array}$ & $\begin{array}{l}\text { BSW-12 } \\
\left(\mathrm{mg} / \mathrm{L}^{-1}\right)\end{array}$ \\
\hline $\mathrm{K}^{+1}$ & 34 & 3400 & 3400 & 141,600 & 91100 \\
\hline $\mathrm{Na}^{+1}$ & 409 & 40,900 & 37,690 & 48,700 & 230400 \\
\hline $\mathrm{Mg}^{+2}$ & 1 & $<1$ & 1000 & 0 & 0 \\
\hline $\mathrm{Ca}^{+2}$ & 0.5 & $<1$ & 1000 & 0 & 0 \\
\hline $\mathrm{F}^{-1}$ & 14 & 1400 & 0 & 0 & 1800 \\
\hline $\mathrm{Cl}^{-1}$ & 67 & 6700 & 24,250 & 128,400 & 178600 \\
\hline $\mathrm{NO}_{3}{ }^{-1}$ & 64 & 6400 & 23,000 & $1,310,000$ & 176800 \\
\hline $\mathrm{SO}_{4}^{-2}$ & 167 & 16,700 & 38,600 & 0 & 16100 \\
\hline $\mathrm{HCO}_{3}{ }^{-1}$ & 947 & 70,000 & 0 & 0 & 214300 \\
\hline Si & $\begin{array}{l}27\left(60^{\circ} \mathrm{C}\right) \\
49\left(90^{\circ} \mathrm{C}\right)\end{array}$ & $\begin{array}{l}27\left(60^{\circ} \mathrm{C}\right) \\
49\left(90^{\circ} \mathrm{C}\right)\end{array}$ & $\begin{array}{l}27\left(60^{\circ} \mathrm{C}\right) \\
49\left(90^{\circ} \mathrm{C}\right)\end{array}$ & 0 & 7100 \\
\hline $\mathrm{pH}$ & $9.8-10.2$ & $9.8-10.2$ & 2.7 & 7 & $>12$ \\
\hline
\end{tabular}

\section{Long-Term Aqueous Corrosion Tests}

The general corrosion (GC) rates of Ti Grade 16 calculated from weight-loss data in SAW, SCW and SDW at 60 and $90^{\circ} \mathrm{C}$ for up to 5 years have been obtained at 


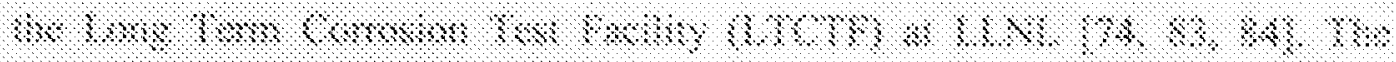

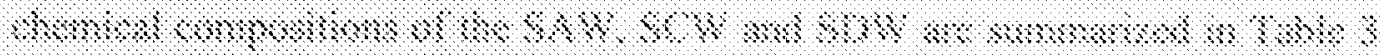

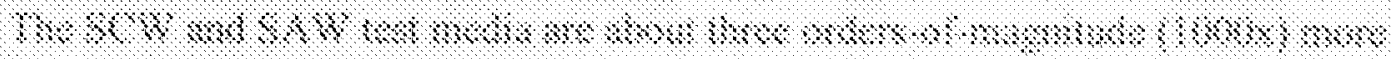

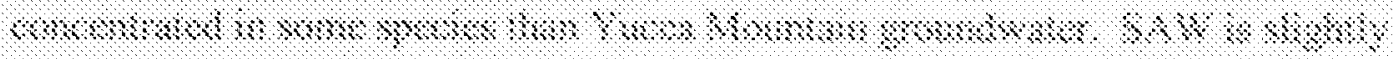

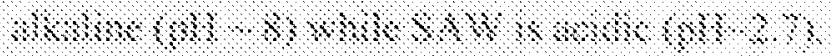

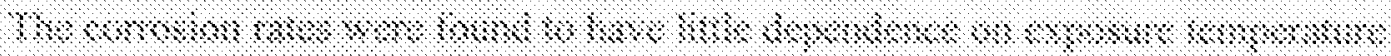
४ $\mathrm{n} \times$ ४०

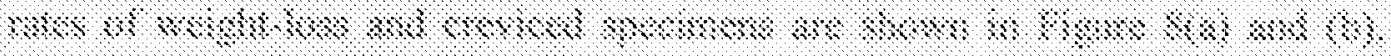

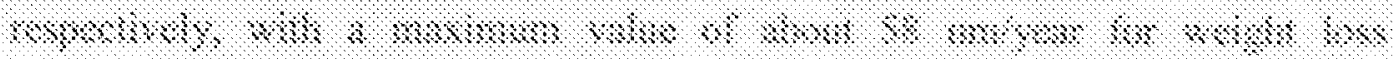

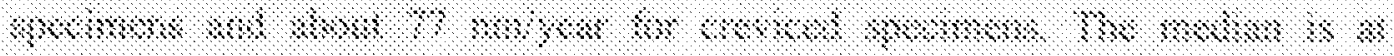
$8 \%$ msmsply.

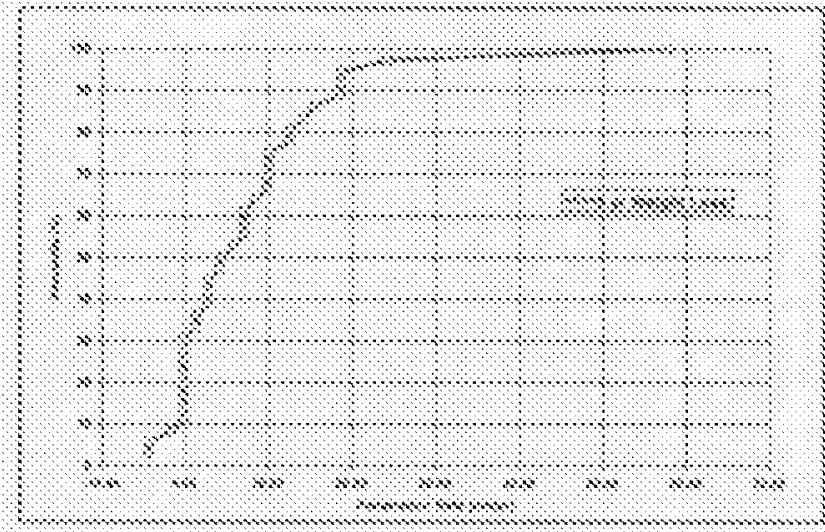

$+4$

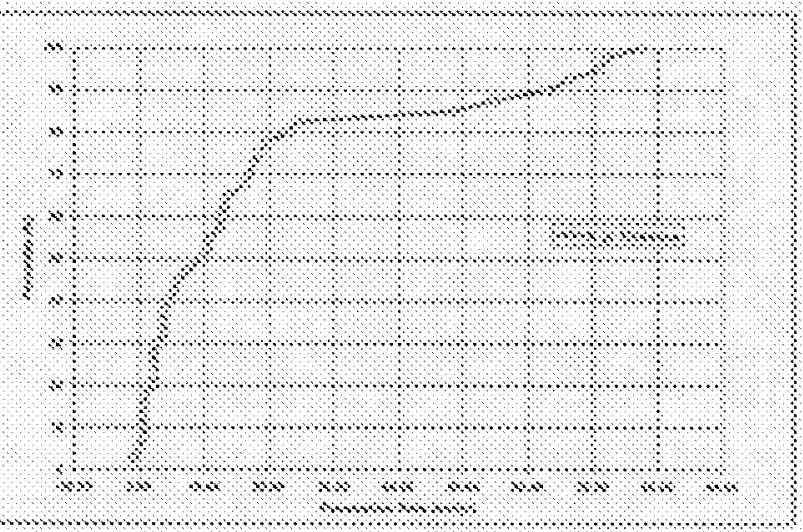

$+3$

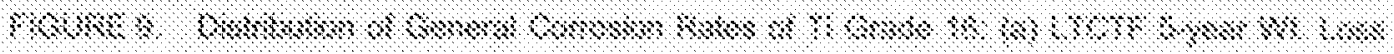

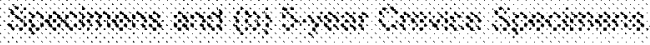




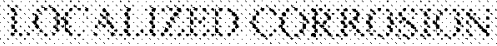

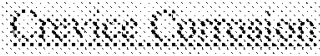

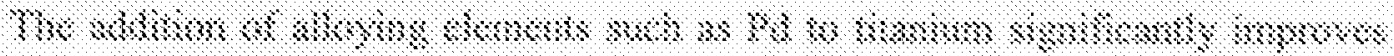

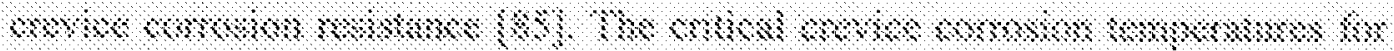

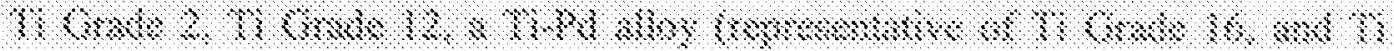

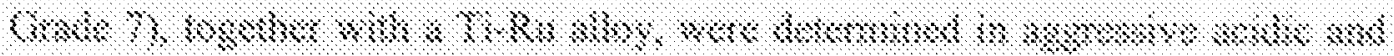
>n

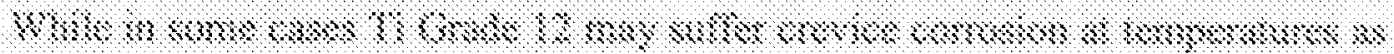

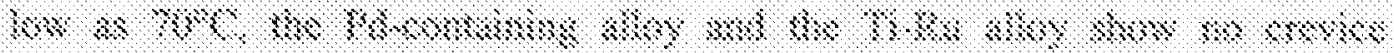

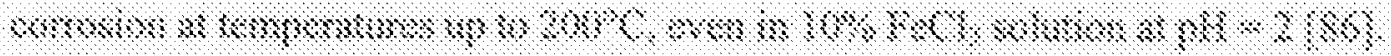

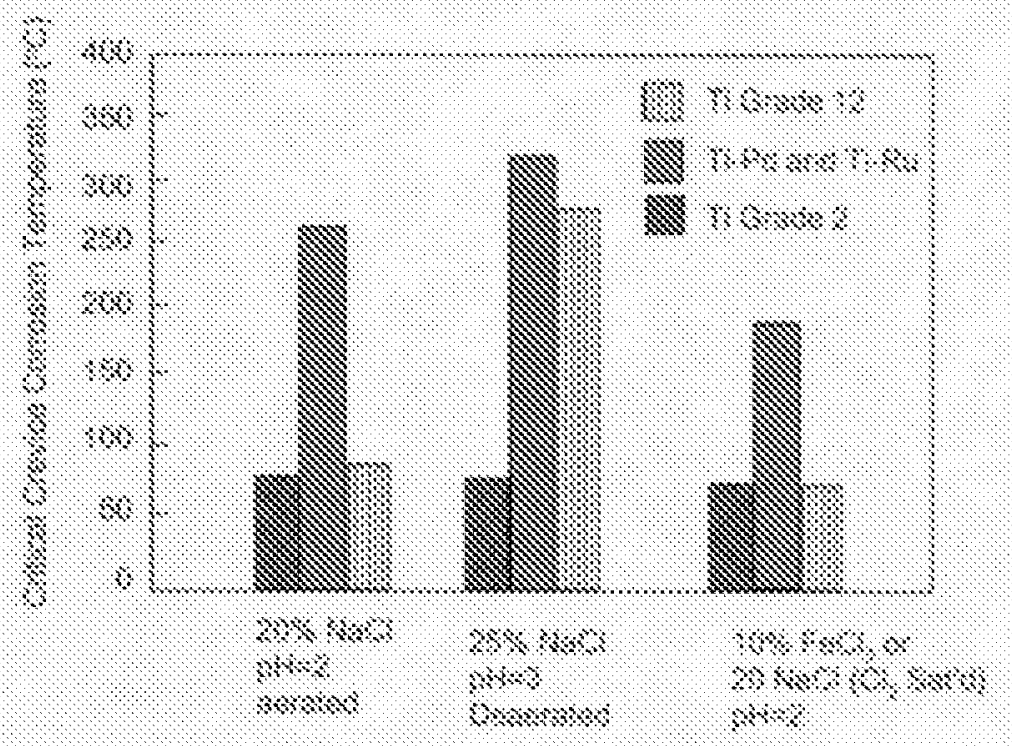

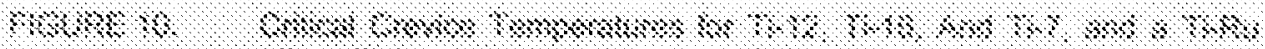

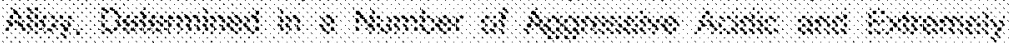
$3,1, \$, \$, \$, \$, \$$ 
Shoesmith et al. [87] showed that the crevice propagation rate and the extent of crevice propagation decrease by orders of magnitude going from $\mathrm{Ti}$ Grade 2 to $\mathrm{Ti}$ Grade 12 to Ti Grade 16.

\section{Pitting}

Pitting of titanium has been studied in some detail $[88,89]$ and reviewed [32]. Commercially pure titanium (Ti Grade 2 ) is extremely resistant to pitting due to the excellent properties of the passive $\mathrm{TiO}_{2}$ film under oxidizing conditions. Pitting potentials at room temperature are in excess of $7 \mathrm{~V}$, and even for temperatures greater than $150^{\circ} \mathrm{C}$ are in the region of $2 \mathrm{~V}$ [32].

$\mathrm{Ti}$ alloys have the potential for formation of intermetallic precipitates which could provide sites for pit initiation, or for the stabilization of an $\alpha / \beta$ phase structure leading to inhomogeneities in the passive film and an increased susceptibility to film breakdown. However, additions of $\mathrm{Ni}$ and Mo (Ti Grade 12) and Pd (Ti Grades 7 and 16) do not adversely affect the pitting potential. These observations, and the influence of the impurity $\mathrm{Fe}$, are summarized in Figure 12. The pitting potential is shown to be normally distributed around a conservatively low mean value of $\sim 7 \mathrm{~V}$ [55]. The horizontal arrow represents the small influence of chloride concentration. This figure was constructed for a temperature of $\sim 100^{\circ} \mathrm{C}$ and pitting potentials would be expected to be higher at lower temperatures [88]. The range of corrosion potentials achievable under repository conditions is approximately that shown, and one can be confident that pitting of 


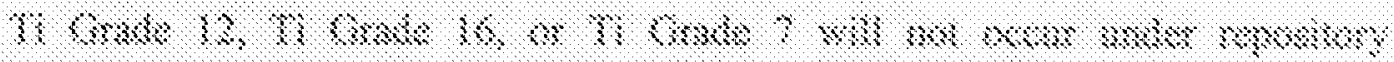

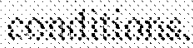

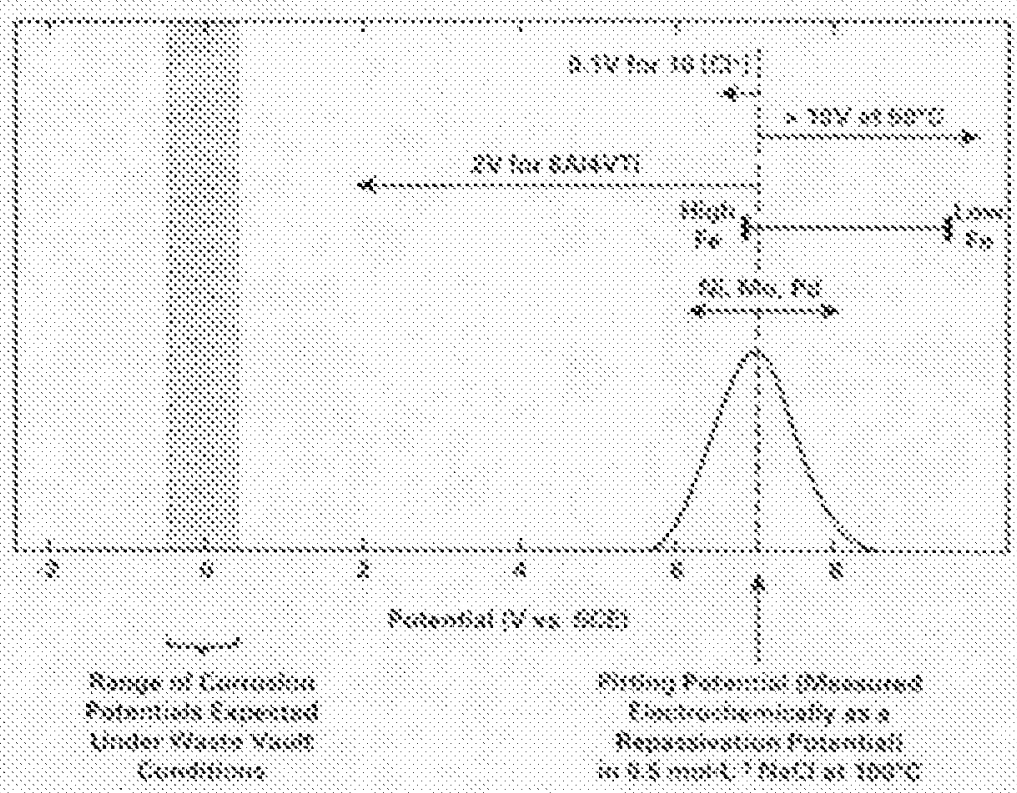

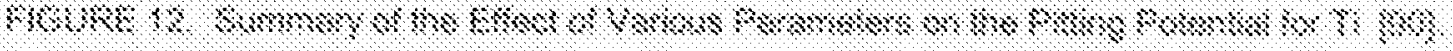

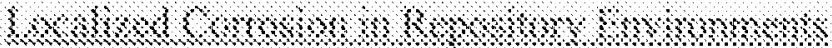

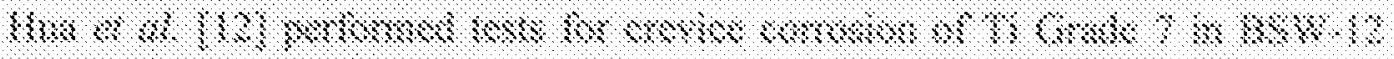

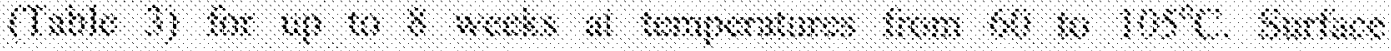

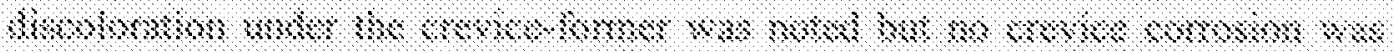

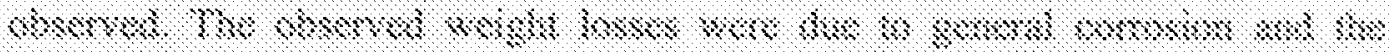

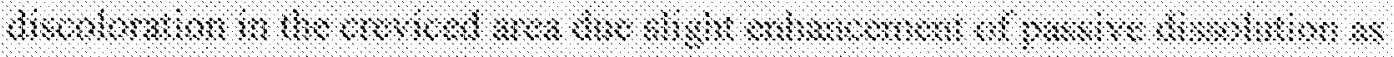

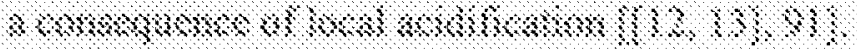

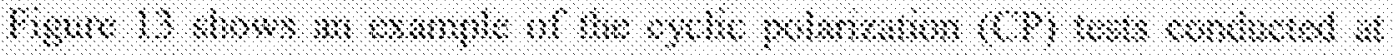

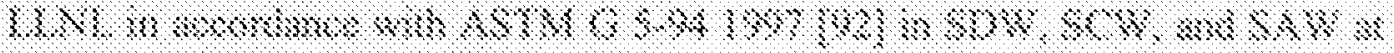

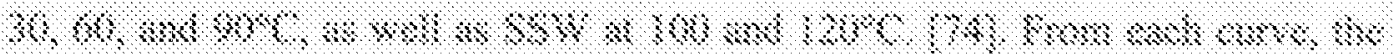




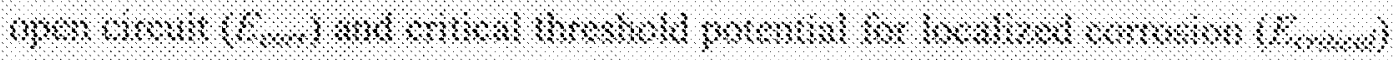

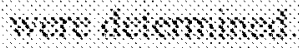

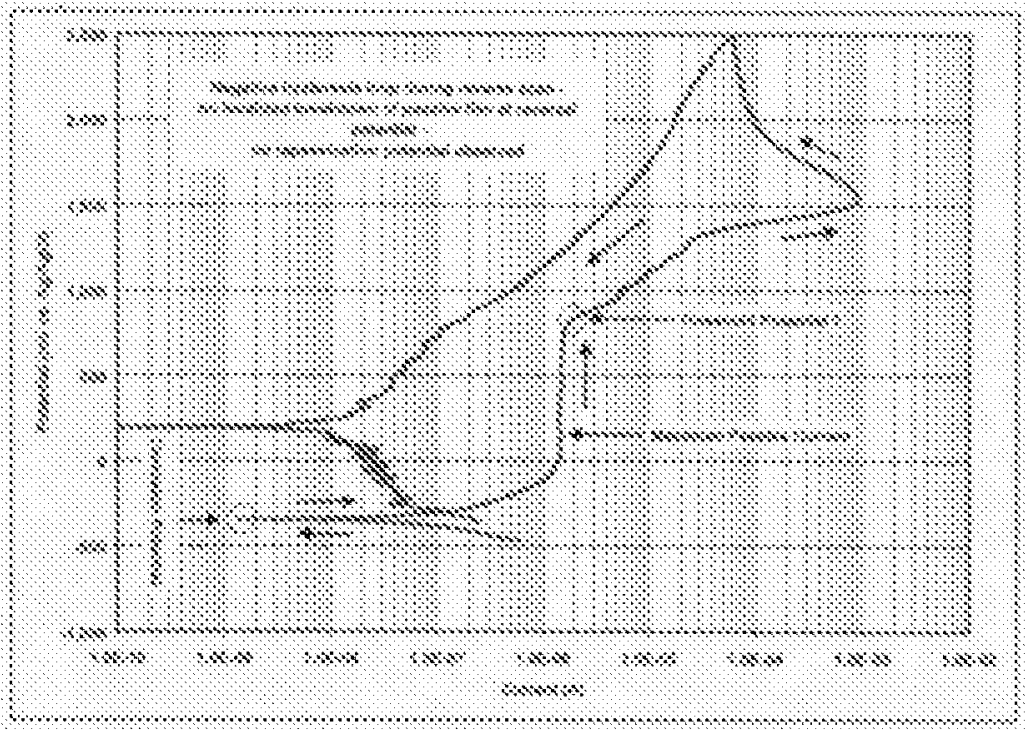

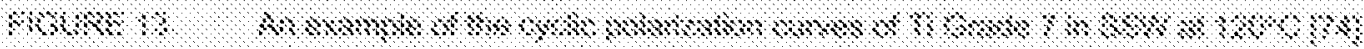

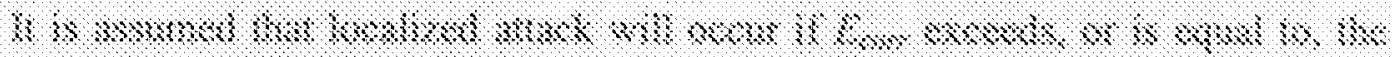

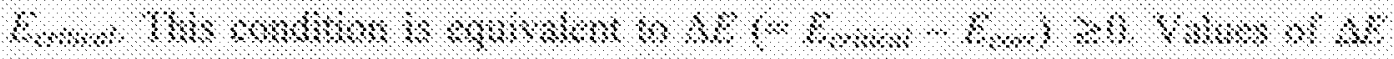

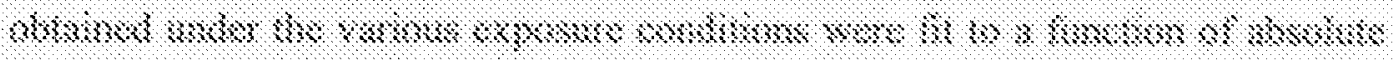

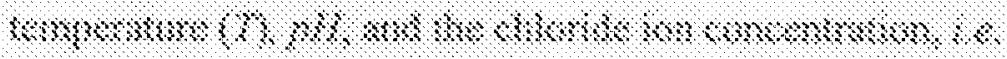

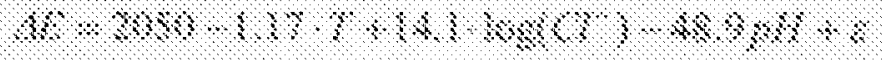

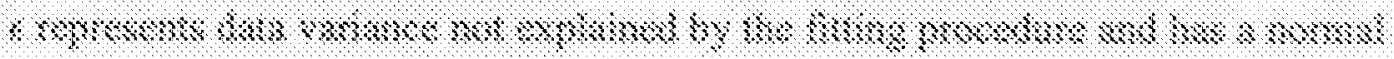

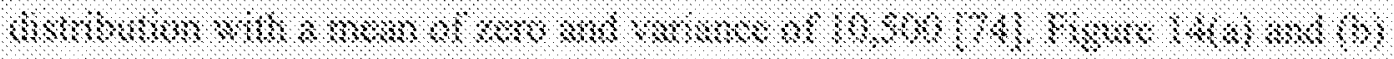

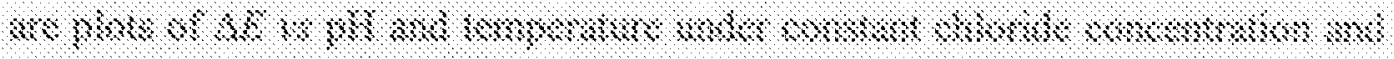

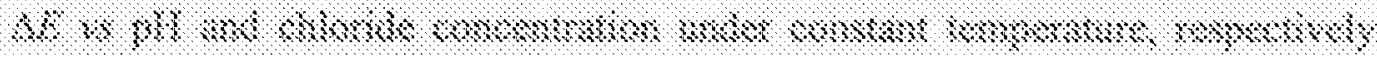




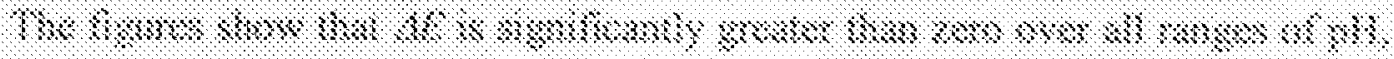

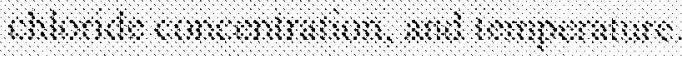

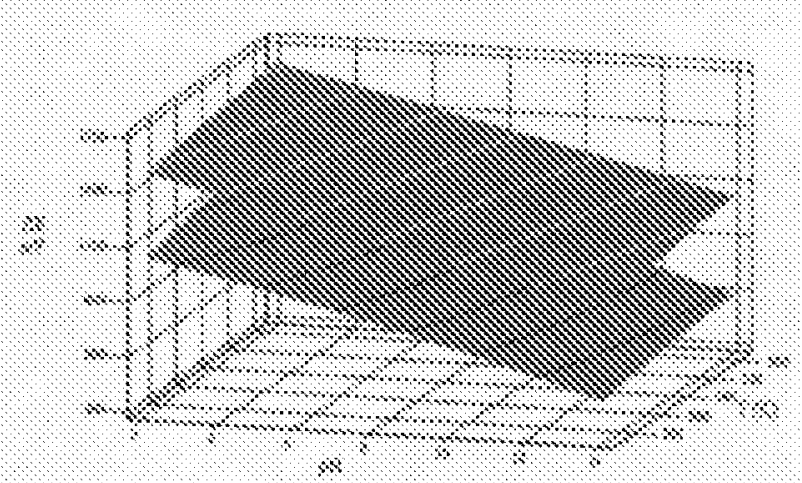

$+3$

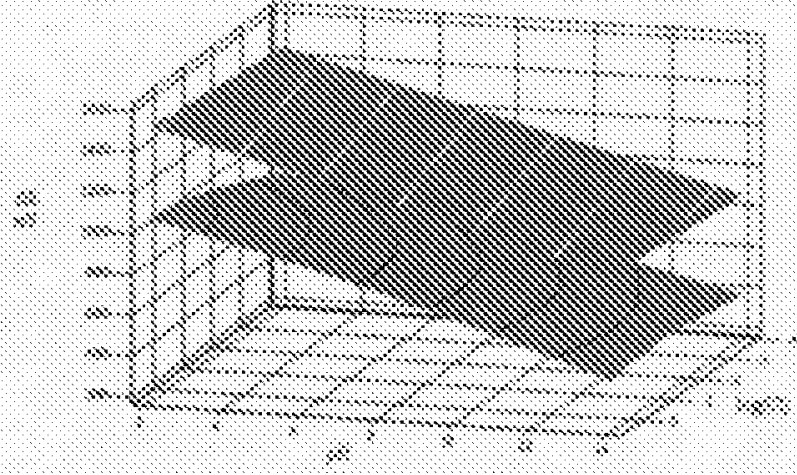

3

H

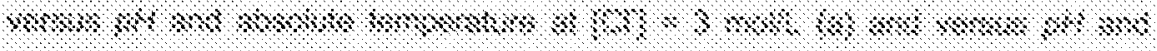

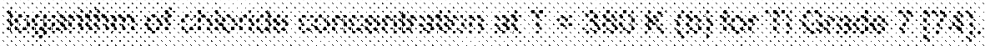

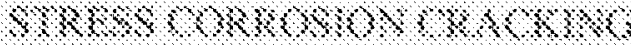

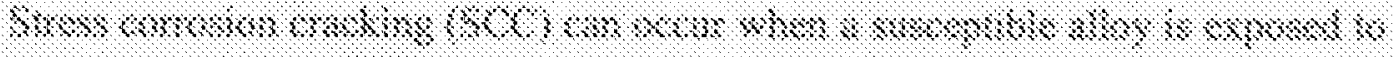

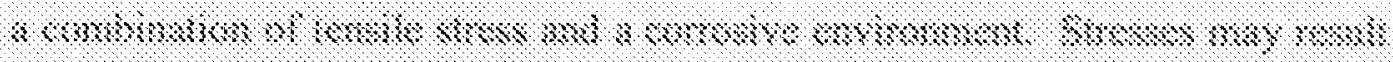

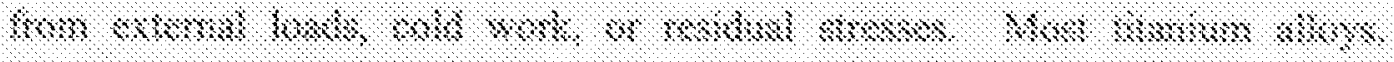

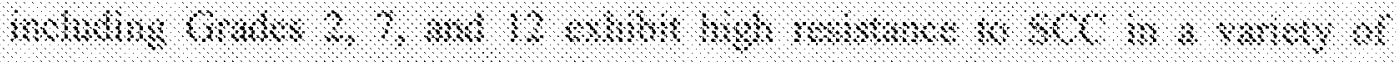

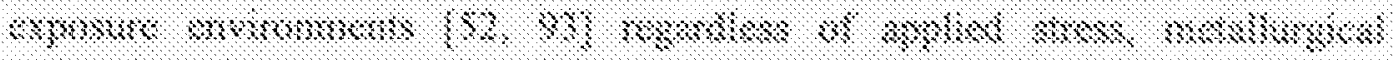
mon

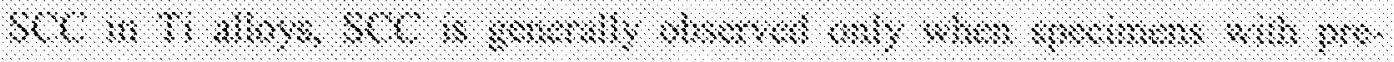

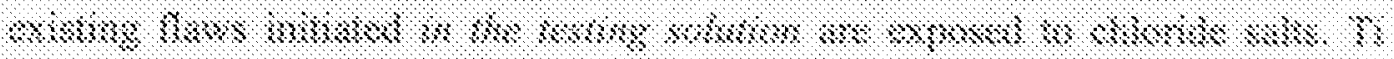

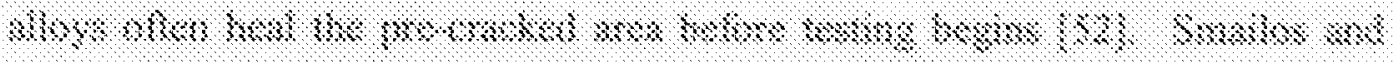

